Article

\title{
Technological and Profitable Analysis of Airlifting in Deep Sea Mining Systems
}

\author{
Wenbin Ma *, Cees van Rhee and Dingena Schott \\ Department of Maritime and Transport Technology, Delft University of Technology, \\ 2628 CD Delft, The Netherlands; C.vanRhee@tudelft.nl (C.v.R.); D.L.Schott@tudelft.nl (D.S.) \\ * Correspondence: W.Ma@tudelft.nl; Tel.: +31-152-781-728
}

Received: 16 June 2017; Accepted: 4 August 2017; Published: 10 August 2017

\begin{abstract}
Airlifting technology utilized in deep-sea mining (DSM) industry was proposed in the 70s of last century, which was triggered by the discovery of vast amounts of mineral resources on the seabed. The objective of this paper is to assess the technological feasibility and profitability analyses in terms of solid production rate, energy consumption per tonnage of mineral, and profitability per tonnage of mineral. The effects of submergence ratio, pipe diameter, particle diameter, mining depth, and gas flux rate are investigated. The analysis is based on a numerical calculation performed in a Matlab environment. The research reported in this paper can assist to select an optimal transport plan for DSM projects depending on its solid production rate, energy consumption, and profitability.
\end{abstract}

Keywords: energy consumption; profitability; pipe diameter; submergence ratio; solid production rate; technological feasibility

\section{Introduction}

In the DSM industry, airlifting is one of the most widely researched technologies equipped with the corresponding facilities, e.g., collecting machine (CM) [1]. Airlifting uses compressed gas to lift the liquid-gas or solid-liquid-gas multiphase flow [2]. It is also used in other industries, such as in chemical industry to transport toxic substances and sewage treatment plants [3]. Although the airlifting transport in DSM has been researched for a long time, until now there is no corresponding commercial scaled DSM project in progress. Technological feasibility and profitability analyses are two of the major considerations for its industrialization [4].

A lot of experimental and theoretical analyses of airlifting technology utilized in the DSM industry started in the 70s of last century, which was triggered by the discovery of vast amounts of manganese nodules on the seabed of depth ranging from 4000 to $6000 \mathrm{~m}$ [5]. Yoshinaga and Sato [6] proposed a numerical modeling method of the airlifting pump depending on momentum equation analysis, which was validated by a vertical pipe lifting system with height of $6.74 \mathrm{~m}$ and diameter of 26 and $40 \mathrm{~mm}$, respectively. In Yoshinaga and Sato's research, the flux rates of solid and gas are given parameters to calculate the liquid flux rate, which does not agree with the realistic working condition. Actually, the gas flux rate is the given parameter and the flux rates of solid and liquid are calculated parameters. Additionally, Yoshinaga and Sato's model is created for uniform particles size distribution [3]. Kassab et al. [3] innovated Yoshinaga and Sato's model by taking the relationship between the liquid and gas flux rates into consideration, which was validated by a vertical pipe lifting system with height of $3.75 \mathrm{~m}$ and diameter of $25.4 \mathrm{~mm}$. In the numerical calculation model proposed by Yoshinaga and Sato, the compressibility of gas is neglected because of the small-scaled experiments. Hatta et al. [5] proposed an airlifting numerical model depending on the solid-liquid mass conservation equations, two momentum equations, and an equation for the solid-liquid volumetric fractions. Additionally, Hatta et al. [7] analyzed a special kind of pipe with an abrupt diameter 
enlargement. Hatta et al. [5,7] utilized the multifluid method to predict the performances of airlifting pumps, which can be used to calculate the gas flux rate up to $45 \mathrm{~m} / \mathrm{s}$. However, Hatta et al. [5,7] admitted that it is quite difficult to establish the transitional situation of the multiphase flow in a pipe system. Margaris and Papanikas [8] proposed an airlifting numerical method by analyzing the fundamental conservation equations of flow continuity and momentum. Hong et al. [9] analyzed pipe inclination effects of airlifting water pump by experiments. They investigated the airlifting performance as a function of the variation of inclination angles. Nam-Cheol et al. [10] studied the airlifting pump with air jet nozzle analyzing its performance influenced by submerged depth, lifting head, and gas flux rate. Researches of both Hong et al. and Nam-Cheol et al. focused on the experiments and did not consider the corresponding theoretical explanation and analysis for their experimental data. Fan et al. [11] researched airlifting pump performances utilized in an artificial upwelling. Almost all of these theoretical and experimental investigations are far away from the industrial scaled working conditions of DSM. These realistic conditions need to be considered concerning the scale effects between the up-scaled model and its industrial scaled prototype. Additionally, no research has considered all related parameters that can influence the airlifting performances in DSM projects.

Based on the literature review, airlifting technological consideration in DSM industry focuses on the transport performances influenced by the submergence ratio which is defined as the ratio between submergence and the total length of the pipe, mining depth, pipe diameter, gas flux rate, and particle diameter [5-11]. For the technological analysis of vertical transport in DSM industry, energy consumption lifting per tonnage of mineral and solid production rate were introduced by Ma et al. [12]. These parameters will also be introduced for the technological analysis of airlifting in this paper. Additionally, profitability is another influencing factor for airlifting technology utilized in DSM, which is mainly reflected by a high initial capital expenditure to purchase the related facilities and high operating cost on these facilities, e.g., production support vessel (PSV), seafloor vehicles, transhipment vessels, mineral processing plants, and even the tailings treatment facilities in a later stage $[4,12]$. For the profitable analysis of airlifting technology utilized in DSM, profitability lifting per tonnage of mineral is researched in this paper. The numerical calculation method used in this paper is based on the original models of Yoshinaga and Sato, and Kassab et al., and considers the compressibility of the gas, which is important because of the large mining depth in engineering conditions. Additionally, the numerical calculation method considers the complete parameters, which consists of the submergence ratio, mining depth, pipe diameter, particle diameter, and gas flux rate.

The objective of this paper is to assess the technological feasibility and profitability in terms of solid production rate, energy consumption per tonnage of mineral, and profitability per tonnage of mineral. The effects of submergence ratio, pipe diameter, particle diameter, mining depth, and gas flux rate are investigated. This paper in combination with paper written by Ma et al. [12] can be used as a reference to select a proper transport plan for DSM projects. The paper is arranged as follows. The Section 2 is the theoretical analysis including theoretical models of airlifting momentum, airlifting energy consumption per tonnage of minerals, and profitability of airlifting utilized in DSM systems. In the Section 3, the validations of the numerical calculation method and calculation results of the solid production rate, airlifting energy consumption per tonnage of minerals, and profitability per tonnage of mineral are analyzed and discussed. Finally, in Section 4 conclusions of the conducted research are given.

\section{Theoretical Analysis}

\subsection{Airlifting Momentum Modelling}

The schematic diagram of airlifting is shown in Figure 1 [6]. The airlifting pipe system consists of a solid-liquid two-phase flow happened between gas inlet and seabed, and a solid-liquid-gas three-phase flow happened between pipe outlet and gas inlet as shown in Figure 1. In Figure 1, the letters of $E, I$, $O$ represent two-phase flow entrance, gas inlet, and outlet of mineral mixtures. 


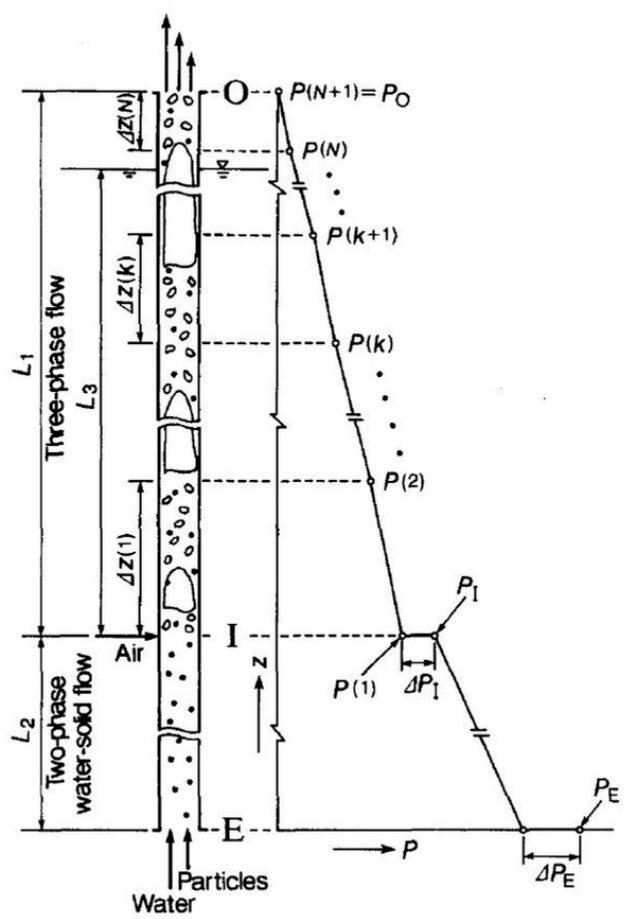

Figure 1. The schematic diagram of an airlifting system [6].

The momentum equation for airlifting can be written as Equation $(1)[3,6]$.

$$
\begin{aligned}
& A\left\{J_{l} \rho_{l} v_{l, E}+\sum_{i=1}^{n} J_{s}(i) \rho_{s}(i) v_{s, E}(i)\right\}-A\left\{J_{g, O} \rho_{g, O} v_{g, O}+J_{l} \rho_{l} v_{l}+\sum_{i=1}^{n} J_{s}(i) \rho_{s}(i) v_{s}(i)\right\} \\
& -\pi D_{i} \int_{E}^{I} \tau_{l s} d z-\pi D_{i} \int_{I}^{O} \tau_{3} d z-A \int_{E}^{I}\left\{\rho_{l} C_{l, 2}+\sum_{i=1}^{n} \rho_{s}(i) C_{s, 2}(i)\right\} g d z \\
& -A \int_{I}^{O}\left\{\rho_{g} C_{g, 3}+\rho_{l} C_{l, 3}+\sum_{i=1}^{n} \rho_{s}(i) C_{s, 3}(i)\right\} g d z+A\left\{\rho_{l} g\left(L_{2}+L_{3}\right)\right\}=0
\end{aligned}
$$

in which $A$ is the pipe cross sectional area $\left(\mathrm{m}^{2}\right), J$ is the volumetric flux $(\mathrm{m} / \mathrm{s}), \rho$ is the density $\left(\mathrm{kg} / \mathrm{m}^{3}\right)$, $v$ is the velocity $[\mathrm{m} / \mathrm{s}]$, the subscripts of $s, l, g$ represent solid particle, liquid, and gas respectively, $\tau$ is the shear stress $\left(\mathrm{N} / \mathrm{m}^{2}\right), D_{i}$ is the pipe diameter $(\mathrm{m}), C$ is the volume concentration $(-), 2,3$ represent two-phase flow and three-phase flow respectively, $i$ represents the type of different particles.

For the solid-liquid two-phase flow, solid and liquid are regarded as incompressible. For the solid-liquid-gas three-phase flow, as density and flux rate of gas are easily influenced by surrounding pressure, Yoshinaga and Sato proposed to divide the up-riser pipe into $N$ elements [6]. The third term of Equation (1) is written as Equation (2) $[3,6]$.

$$
\pi D_{i} \int_{E}^{I} \tau_{l s} d z=A\left\{\frac{\Delta P_{f . l s}}{\Delta z} L_{2}+\Delta P_{E}\right\}
$$

in which $\Delta P_{f . l s} / \Delta z$ is the friction pressure gradient in solid-liquid flow $(\mathrm{Pa} / \mathrm{m}), \Delta P_{E}$ is the pressure decrease at the entrance position $(\mathrm{Pa})$.

The fourth term in Equation (1) can be rewritten as Equation (3) [13].

$$
\pi D_{i} \int_{E}^{I} \tau_{3} d z=A\left\{\sum_{k=1}^{N} \frac{\Delta P_{f .3}(k)}{\Delta z(k)} \Delta z(k)+\Delta P_{I}\right\}
$$

in which $\Delta P_{f .3}(k) / \Delta z(k)$ is the friction pressure gradient in solid-liquid-gas flow $(\mathrm{Pa} / \mathrm{m}), \Delta P_{I}$ is the pressure decrease at the gas inlet position $(\mathrm{Pa})$. 
In the airlifting numerical calculation process, the velocity relationship of solid particles needs to be considered. For three-phase flow, the velocity of particles can be calculated as Equation (4) [14].

$$
v_{S}(i)=c \frac{m}{\rho_{A}}+v_{s w}(i)
$$

in which $c$ is the distribution coefficient (-), $m$ is the mass flux of the three-phase flow $\left(\mathrm{kg} / \mathrm{m}^{2} \cdot \mathrm{s}\right), \rho_{A}$ is the apparent density of the three-phase mixture $\left(\mathrm{kg} / \mathrm{m}^{3}\right), v_{s w}$ is the wall affected settling velocity in a three-phase flow $(\mathrm{m} / \mathrm{s})$.

For solid-liquid two-phase flow, the volume concentration of solid, liquid can be calculated through solving Equation (5) [15].

$$
C_{l}^{2}+\left(\frac{-v_{s l}-J_{l}-J_{s}}{v_{s l}}\right) C_{l}+\frac{J_{l}}{v_{s l}}=0
$$

in which $v_{s l}$ is the slip velocity, which is related to the particle diameter, pipe diameter, settling velocity, and solid volume concentration $(\mathrm{m} / \mathrm{s})$.

The volume concentration of the gas can be calculated as Equation (6) [6].

$$
C_{g}=\left[1+0.4 \frac{\rho_{g}}{\rho_{l s, 3}}\left(\frac{m}{\rho_{g} J_{g}}-1\right)+0.6 \frac{\rho_{g}}{\rho_{l s, 3}}\left(\frac{m}{\rho_{g} J_{g}}-1\right)\left\{\frac{\frac{\rho_{l s, 3}}{\rho_{g}}+0.4\left(\frac{m}{\rho_{g} J_{g}}-1\right)}{1+0.4\left(\frac{m}{\rho_{g} J_{g}}-1\right)}\right\}^{0.5}\right]^{-1}
$$

in which $\rho_{l s, 3}$ is the mean density of the slurry $\left(\mathrm{kg} / \mathrm{m}^{3}\right)$.

Compared to the original model of Yoshinaga and Sato, the significant difference of gas density and flux rate, which are caused by the large mining depth in engineering conditions, are taken into consideration, see Equation (7) [15].

$$
\left\{\begin{array}{l}
J_{g_{-} z}=\frac{J_{g_{-} 0} \cdot P_{0}}{P_{z}} \\
\rho_{g_{-} z}=\frac{\rho_{g} \cdot P_{z}}{P_{0}}
\end{array}\right.
$$

in which $P_{0}$ is the initial gas pressure $(\mathrm{Pa}), P_{z}$ is the gas pressure at the vertical position of $z(\mathrm{~Pa}), \rho_{g_{-} 0}$ is the initial gas density $\left(\mathrm{kg} / \mathrm{m}^{3}\right), \rho_{g_{-} z}$ is the gas density at the vertical position of $z\left(\mathrm{~kg} / \mathrm{m}^{3}\right)$.

Based on Equations (1)-(7), the airlifting process in the vertical pipe system can be calculated. After the establishment of airlifting numerical model, the next section will focus on the energy consumption calculation.

\subsection{Energy Consumption per Tonnage of Mineral Modelling}

The energy consumption of airlifting system is closely related to the compressor's expansion type, which is defined as an isothermal expansion in this paper [11]. The airlifting efficiency can be calculated as Equation (8) [15,16].

$$
\eta_{a}=\left(1-\frac{\rho_{l}}{\rho_{s}}\right) \frac{E_{u}}{E_{t}}
$$

in which $E_{u}$ is the useful energy consumption of the airlifting system $(J), E_{t}$ is the total energy consumption of the airlifting system $(J)$.

The useful energy consumption of the airlifting system is defined as the anti-gravitational energy consumption of lifting mineral solids from seabed to pipe outlet. It can be calculated as Equation (9) $[11,15,16]$.

$$
E_{u}=\rho_{s} \cdot A \cdot J_{s} \cdot g \cdot\left(L_{2}+L_{1}\right)
$$

in which $L_{1}$ and $L_{2}$ are lengths of different segments of the vertical pipe (m), see Figure 1. 
The total energy consumption of the airlifting system is the isothermal energy consumption of the compressor. It can be calculated as Equation $(10)[11,15,16]$.

$$
E_{t}=J_{g_{-} a t m} \cdot A \cdot \ln \frac{P_{I}}{P_{a t m}}
$$

in which $J_{g_{-} a t m}$ is the gas flux under atmospheric pressure $(\mathrm{m} / \mathrm{s}), P_{I}$ is the pressure at the inlet $(\mathrm{Pa})$, $P_{a t m}$ is the atmospheric pressure (Pa).

Additionally, the energy consumption per tonnage of minerals is also an important parameter, which can be calculated as Equation (11) [12].

$$
E_{\text {ton }}=\frac{E_{t}}{Q_{s}}
$$

in which $Q_{s}$ is the mineral solids production rate (ton).

\subsection{Profitability per Tonnage of Mineral Modelling}

The profitability analysis of airlifting utilized in DSM systems focuses on the difference between gross income and total expenditure derived from minerals. The total expenditure of an airlifting system is divided into capital expenditure (CAPEX) and operational expenditure (OPEX) [12,17].

$$
M_{t}=M_{c}+M_{o}
$$

in which $M$ represents the cost (\$), $c$, o represent the initial capital expenditure and operation expenditure.

The $M_{c}$ and $M_{o}$ in Equation (12) can be calculated as Equation (13) [12,18].

$$
\left\{\begin{array}{l}
M_{c}=M_{\mathcal{C}_{-} m}+M_{\mathcal{C}_{-} t}+M_{\mathcal{C}_{-} p} \\
M_{o}=M_{0_{-} m}+M_{0_{-} t}+M_{\mathcal{O}_{-} p}
\end{array}\right.
$$

in which $m, t, p$ represent the mining system, transport system, and processing plant respectively. The initial capital expenditure of the mining system is spent on different kinds of seafloor vehicles.

The pipe system of airlifting technology in DSM projects consists of a major up-riser pipe and an auxiliary air-injection pipe, which is required to calculate initial capital cost of pipe systems [12].

$$
\left\{\begin{array}{l}
n_{r}=\frac{\left(L_{1}+L_{2}\right)}{l_{p r}} \\
n_{I}=\frac{L_{1}}{l_{p I}}
\end{array}\right.
$$

in which $n_{r}$ and $n_{I}$ are the up-riser and air-injection pipe elements number (-), $l_{p r}$ and $l_{p I}$ are the pipe element length of the up-riser pipe and air-injection pipe respectively $(\mathrm{m})$. Therefore, the initial capital cost of the transport system can be calculated as Equation (15) [12].

$$
M_{c_{-} t}=M_{s v}+\pi \cdot \rho_{p} \cdot M_{m_{-} p} \cdot\left(1+\varepsilon_{1}\right) \cdot\left\{l_{p r} \cdot\left(r_{r_{-} 1}^{2}-r_{r_{-} 2}^{2}\right) \cdot n_{r}+l_{p I} \cdot\left(r_{I_{-} 1}^{2}-r_{I_{-} 2}^{2}\right) \cdot n_{I}\right\}+M_{-o t}
$$

in which $M_{s v}$ is the initial capital cost on the shipping vessel including production support vessel and trans-shipment vessels (\$), $M_{m \_} p$ is the manufacturing cost of the pipeline system (\$), $\rho_{p}$ is the material density of the pipe $\left(\mathrm{kg} / \mathrm{m}^{3}\right), \varepsilon_{1}$ is the pipe manufacturing price factor which means the added value of materials $(-), r$ is the radius of pipelines (m), 1, 2 represent the external and internal radius of pipelines (m), $M_{-}$ot is the other transport cost (\$). 
The operation expenditure of the mining system, transport system, and processing system can be calculated as Equation (16) [12].

$$
\left\{\begin{array}{l}
M_{o_{-} m}=M_{m \_m a}+M_{m \_p e} \\
M_{o_{-} t}=M_{t \_m a}+M_{t \_p e} \\
M_{o_{-} p}=M_{p_{-} l a}+M_{p_{-} m a}+M_{p_{-} p e}
\end{array}\right.
$$

in which $m a, p e$, and $l a$ represent the maintenance, power and energy consumption, and labor expenditures.

The $M_{p_{-} l a}$ in Equation (16) can be calculated as Equation (17) [12].

$$
M_{p_{-} l a}=\sum_{j=1}^{N} \sum_{i=1}^{n_{s}} W_{i} \cdot(1+a)^{N}
$$

in which $W_{i}$ is the salary for the staff $i\left(\$ /\right.$ year), $n_{s}$ is the staff number $(-), N$ is the mining period (year), $a$ is the inflation rate (-).

The maintenance, power, and energy consumption expenditures can be calculated as Equation (18) [12].

$$
\left\{\begin{array}{l}
M_{j_{-} m a}=\sum_{i=1}^{N} 24 \cdot s \cdot Q_{s} \cdot K_{j_{-} k} \cdot(1+a)^{N} \\
M_{j_{-} p e}=\sum_{i=1}^{N} 24 \cdot s \cdot E_{k} \cdot R \cdot(1+a)^{N}
\end{array}\right.
$$

in which $j$ represents the mining system, transport system, and the processing system respectively, $K$ is the maintenance fee every year $(\$ /$ ton $), R$ is the power and energy consumption price $(\$ / \mathrm{kWh})$, $E_{k}$ is the energy consumption $(\mathrm{kWh} / \mathrm{h}), s$ is the mean working days per year.

The income derived from minerals can be calculated as Equation (19) [12].

$$
M_{i n}=\sum_{i=1}^{N}\left(24 \cdot s \cdot Q_{s} \cdot M_{i, m m} \cdot(1+a)^{N}\right)
$$

in which $M_{i, m m}$ is the mineral ore price which is set to be $95 \$ /$ ton.

The profitability per tonnage of mineral can be calculated as Equation (20) [12].

$$
M_{\text {ton }}=\frac{M_{b e}}{\sum_{i=1}^{N}\left(24 \cdot s \cdot Q_{s}\right)}=\frac{M_{i n}-M_{t}+M_{r e}}{\sum_{i=1}^{N}\left(24 \cdot s \cdot Q_{s}\right)}
$$

in which $M_{b e}$ is the pure benefit of DSM project (\$), $M_{r e}$ is the residual value (\$).

\section{Results and Discussions}

\subsection{Validations}

\subsubsection{Model Validated by Experimental Data of Yoshinaga and Sato}

The numerical calculation model of Equations (1)-(7) proposed by Yoshinaga and Sato [6] is used in this section. Additionally, the experimental data found in Yoshinaga and Sato's paper can be used as the validation data. In Yoshinaga and Sato's experiment [6], spherical and uniform particles are used, as follows: C1-Sp-06, which density and diameter are $2540 \mathrm{~kg} / \mathrm{m}^{3}$ and $6.1 \mathrm{~mm}$ respectively, C1-Sp-10, which density and diameter are $2540 \mathrm{~kg} / \mathrm{m}^{3}$ and $9.9 \mathrm{~mm}$ respectively, and C2-Sp-06, which density and diameter are $3630 \mathrm{~kg} / \mathrm{m}^{3}$ and $9.5 \mathrm{~mm}$ respectively. In Figure 2, nine types of airlifting conditions are shown with solid flux rate ranging from 0.014 to $0.095 \mathrm{~m} / \mathrm{s}$. Axis $x$ represents the experimental data of liquid flux rate from 0 to $1 \mathrm{~m} / \mathrm{s}$. Axis y represents the calculation data of liquid flux rate from 0 
to $1 \mathrm{~m} / \mathrm{s}$. The closer the data points are to the diagonal, the more accurate the calculation results. The majority of data points are located in the area within $10 \%$ deviation of the diagonal, which indicates that the model is sufficiently accurate.

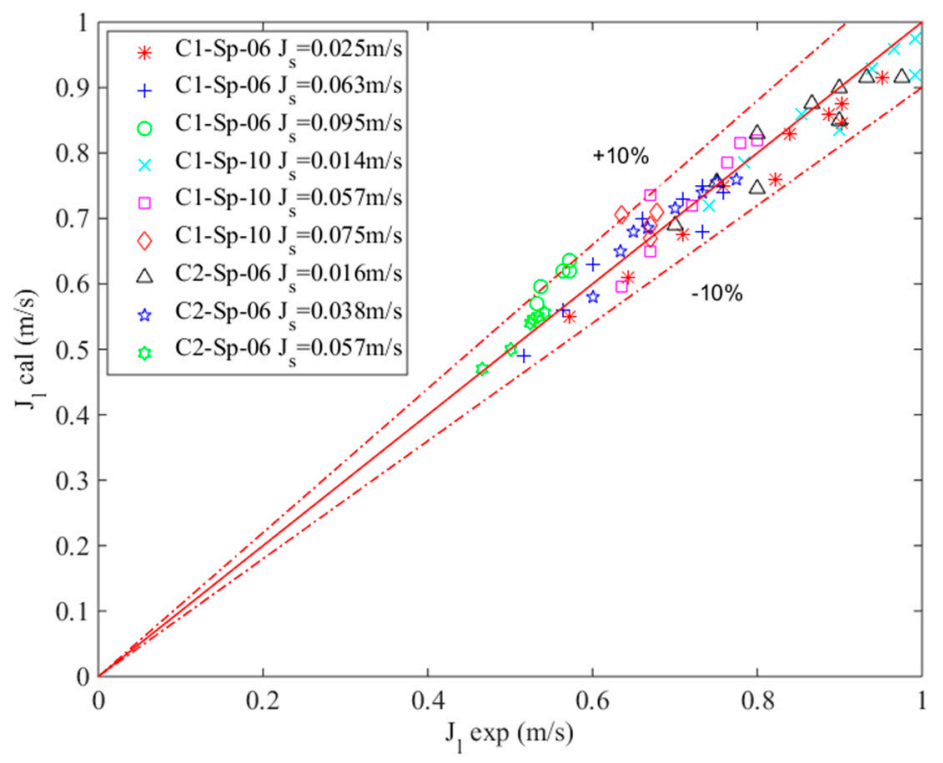

Figure 2. Validation results by experimental data from Yoshinaga and Sato [6].

\subsubsection{Model Validated by Experimental Data of Kassab et al.}

In Yoshinaga and Sato's model of simulating a solid-liquid-gas airlifting system, the flux rates of gas and solid are designated as a pair of original values. Then based on momentum balance equation, the flux rate of liquid is determined [6]. Kassab et al. utilize the Stenning and Martin equation, see Equation (21), combining with momentum method to solve the flux rates of solid and liquid directly from gas flux rate [19].

$$
\frac{L_{3}}{L_{1}}-\frac{1}{1+\left(V_{g} /\left(s_{l} \cdot V_{l}\right)\right)}=\frac{J_{l}^{2}}{2 g \cdot L_{1}}\left[\left(K_{c}+1\right)+\left(K_{c}+2\right) \frac{V_{g}}{V_{l}}\right]
$$

in which $V_{g}, V_{l}$ are the volume flow rate of gas and liquid $\left(\mathrm{m}^{3} / \mathrm{s}\right), s_{l}$ is the slip factor $(-), K_{c}$ is the friction factor (-).

The $s_{l}$ in Equation (21) can be calculated with Equation (22) [20].

$$
s_{l}=1.2+0.2 \frac{V_{g}}{V_{l}}+\frac{0.35 \cdot \sqrt{g \cdot D_{i}}}{J_{l}}
$$

The $K_{c}$ in Equation (21) can be calculated with Equation (23) [19].

$$
K_{c}=\frac{4 \cdot f \cdot L_{1}}{D_{i}}
$$

in which $f$ is the friction coefficient calculated by Colebrook-White equation, which can be calculated as Equation (24) [21].

$$
f=0.25 \cdot\left[\log \left(\frac{\frac{\varepsilon}{D_{i}}}{3.7}+\frac{5.74}{\operatorname{Re}^{0.9}}\right)\right]^{-2}
$$

in which $\varepsilon$ is the pipe wall roughness (m), Re is the liquid Reynolds number (-). 
Based on Equations (21)-(24), the innovated numerical method of airlifting by Kassab et al. is validated in Figure 3. Kassab et al. investigated airlifting performances influenced by submergence ratio and particle diameter [3]. In Figure 3, particle diameters of 4.75, 7.10, and $9.50 \mathrm{~mm}$, and submergence ratio of $0.50,0.72$, and 0.78 , are calculated. Alike the validation principle described in Figure 2, the closer the data points to the diagonal, the more accurate the calculation results are. As most of data points are located in the area within $10 \%$ deviation of the diagonal, the calculation system used in this paper is sufficiently accurate.

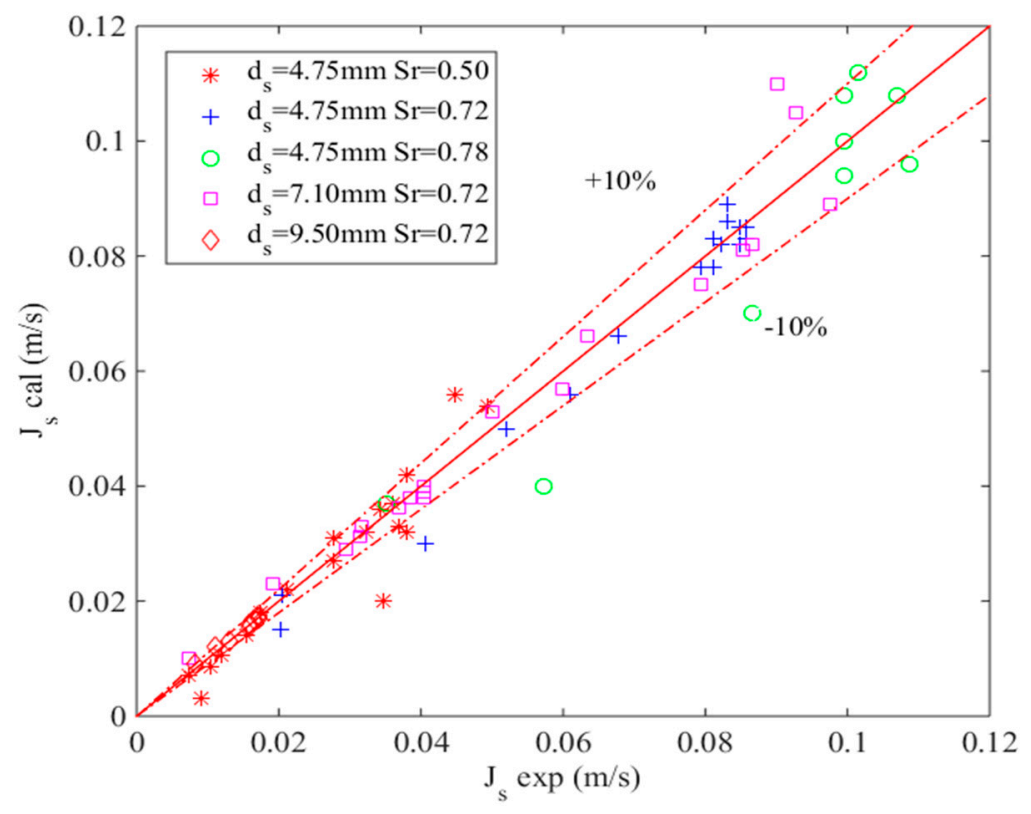

Figure 3. Validation results by experimental data from Kassab et al [3].

\subsubsection{Scale Effect}

Scale effect arises due to differences between an up-scaled model and its industrial scaled prototype, which leads to some deviations between the simulation results [22]. The scale ratio between the general up-scaled model and industrial scaled prototype of airlifting model in DSM projects can be up to 500 600, which is much larger than that in normal mechanical and hydraulic simulations $[3,6,23]$. Additionally, most parameters of the experimental and theoretical airlifting modeling researches are smaller than the industrial scaled airlifting parameters in DSM projects $[3,6]$. The most frequently used method to compensate scale effect is to distort model geometry by giving up exact geometric similarities or change the related parameter appropriately, e.g., model roughness [22]. In this section, flow regime conditions both in the experiments of Yoshinaga and Sato and Kassab et al., and the following large-scale calculation case are taken into consideration. Because of the lack of theoretical research on solid-liquid-gas three-phase flow regimes in a vertical pipe system, the flow regime of gas-liquid flow in a vertical pipe system is used. In the airlifting vertical pipe system, there exist five different type flow regimes including bubble, slug, froth, annular, and finely dispersed bubbles depending on the velocity and geometry of the lifting components $[15,24]$. This thought has already been used by the other researchers in the DSM field [25]. The flow regime transitions are calculated as Equations (25)-(29) [15,24].

$$
\begin{gathered}
J_{l}=3.0 \cdot J_{g}-1.15 \cdot\left[\sigma \cdot g \cdot\left(\rho_{l}-\rho_{g}\right) / \rho_{l}^{2}\right]^{0.25} \\
J_{l}+J_{g}=4.0 \cdot\left\{\left[D_{i}^{0.429} \cdot\left(\frac{\sigma}{\rho_{l}}\right)^{0.089} / J_{l}^{0.072}\right] \cdot\left[g \cdot\left(\rho_{l}-\rho_{g}\right) / \rho_{l}\right]^{0.446}\right\}
\end{gathered}
$$




$$
\begin{gathered}
J_{g}=J_{l} \\
J_{g}=-J_{l}+\alpha_{s f} \cdot \sqrt{g \cdot D_{i}} \\
J_{g} \cdot \rho_{g}^{0.5}=3.1 \cdot\left[\sigma \cdot g \cdot\left(\rho_{l}-\rho_{g}\right)\right]^{0.25}
\end{gathered}
$$

in which $\sigma$ is the surface tension of the liquid $\left(\mathrm{N} / \mathrm{m}^{2}\right), \alpha_{s f}$ is a factor which is influenced by the airlifting geometries. Equation (25) depicts the regime transition from bubble to slug flow. The following Equations (26)-(29) are corresponding to bubbly to dispersed bubbly flow, froth to dispersed bubbly flow, slug to froth flow, and froth to annular flow. Figure 4 depicts the calculation results of the flow regime.

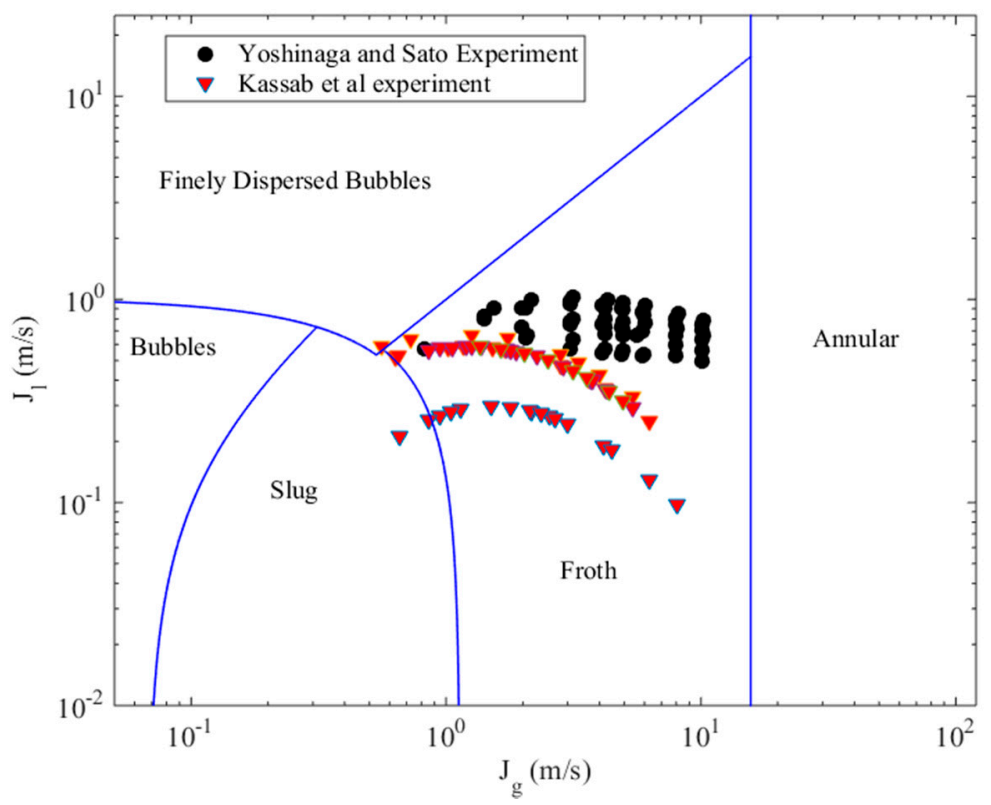

Figure 4. Flow regime figure combining the experimental results of Yoshinaga and Sato and Kassab et al. [3,6].

Analyzing Figure 4, most of the flow regimes in Yoshinaga and Sato, and Kassab's experiments are froth flows, which is limited by the small-scaled gas flux rate. However, for the case studies in this paper, as the gas flux rates change from 30 to $180 \mathrm{~m} / \mathrm{s}$, all the flow regimes in the following calculation system are annular flows. Therefore, besides the scale effects between the up-scaled model and an industrial scaled prototype of airlifting model, flow pattern differences should also be considered in the future research.

\subsection{Solid Production Rate Analysis}

Solid production rate is an important parameter in DSM, which determines the gross income directly; see Equation (19). In this section, the relationships between solid production rate and submergence ratio, mining depth, pipe diameter, particle diameter, and gas flux rate are researched. The parameter changing ranges of airlifting in DSM systems are given as Table 1.

Table 1. The parameters of the airlifting system in DSM.

\begin{tabular}{cccccc}
\hline Parameters & $S_{r}(-)$ & $d_{s}(\mathbf{m m})$ & $D_{i}(\mathbf{m})$ & $J g(\mathbf{m} / \mathbf{s})$ & $H(\mathbf{m})$ \\
\hline Range & $0.985-1.000$ & $1.0-50.0$ & $0.25-0.40$ & $30-180$ & $500-6000$ \\
\hline
\end{tabular}


Figure 5 depicts the relationship between the solid production rate and submergence ratio at different mining depth and gas flux rate with pipe diameter of $0.40 \mathrm{~m}$ and particle diameter of $5.0 \mathrm{~mm}$. Analyzing Figure $5 \mathrm{a}-\mathrm{d}$, it is obvious that with the same gas flux rate the solid production rate of airlifting decreases with the increase of mining depth on the whole. Additionally, when the submergence ratio is set to be $1.000,0.995,0.990$, and 0.985 respectively, there are not so many differences between these calculating conditions. Although with a small changing amplitude, by analyzing the data, it proves that larger submergence ratio may also represent larger solid production rate with the same gas flux rate. It can be explained as that a larger submergence ratio also means lifting a relative smaller vertical distance when the mining depth is the same. Therefore, an airlifting system can lift more minerals with a larger submergence ratio. As submergence ratio is an important parameter in airlifting system, the calculation here is conducted to have an insight of its influencing on industrial scaled DSM working conditions. However, taking into account the actual working conditions, the values of submergence ratio should not be too small, which range from 0.985 to 1.000. Furthermore, when the mining depth is set the same, a larger gas flux rate may not produce a larger solid production rate. For instance, in Figure 5a when the mining depth is 500 and $1000 \mathrm{~m}$ respectively, the airlifting system with gas flux rate of 70 and $90 \mathrm{~m} / \mathrm{s}$ transports the maximum minerals of 497.9 and 428.0 ton/h respectively. However, a larger gas flux rate may always represent a larger range of applicable mining depth. For instance, in Figure 5c, the maximum applicable mining depths of gas flux rate of 30,50, 90 and $150 \mathrm{~m} / \mathrm{s}$ are 1000, 2000, 3500 and $4500 \mathrm{~m}$ respectively. For the airlifting system with gas flux rate of $180 \mathrm{~m} / \mathrm{s}$ at mining depth of $1000 \mathrm{~m}$, there is a sudden decrease of solid production rate. It could be explained as that solid production rate is influenced by both the increased airlifting efficiency and the mining depth which have the conflict effect on the performances of airlifting system.

(a) $\mathrm{S}_{\mathrm{r}}=1.000$

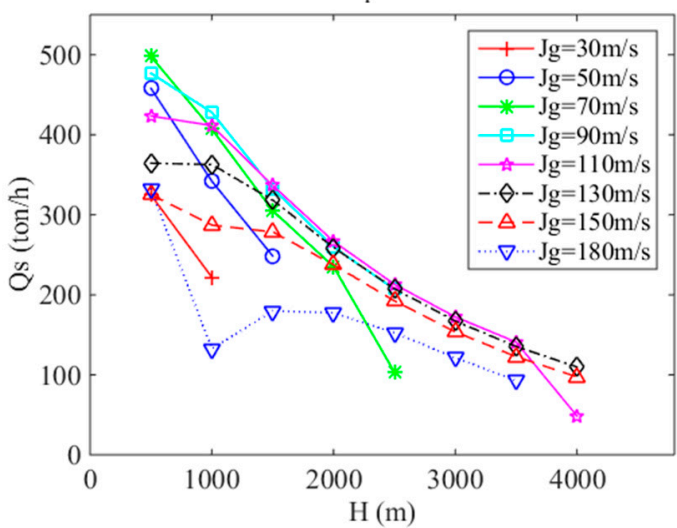

(c) $\mathrm{S}_{\mathrm{r}}=0.990$

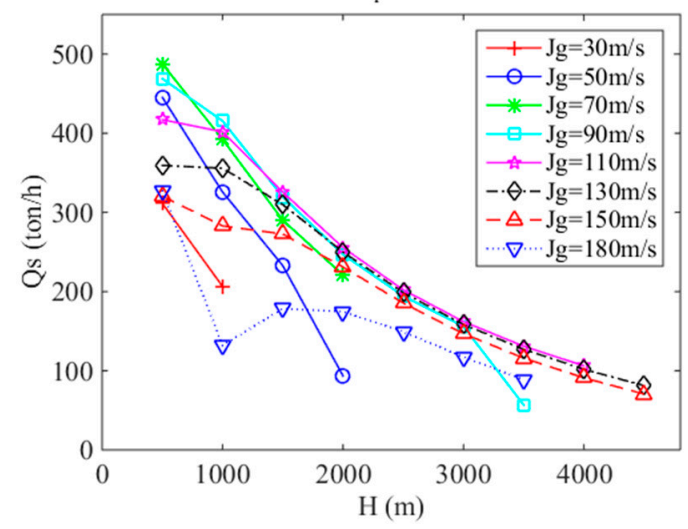

(b) $\mathrm{S}_{\mathrm{r}}=0.995$

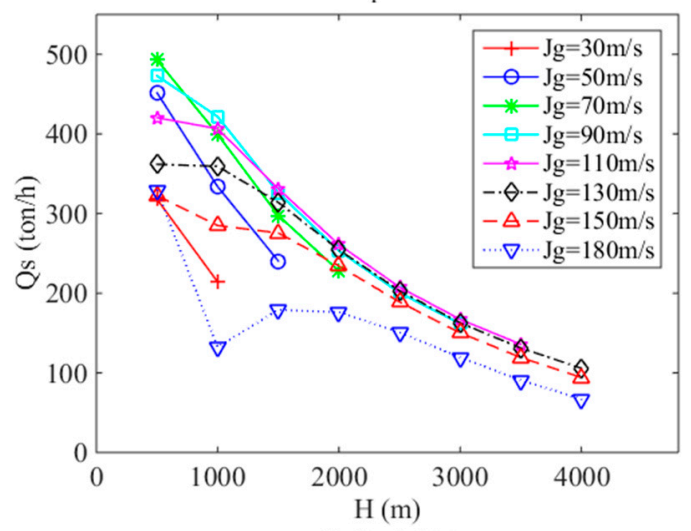

(d) $\mathrm{S}_{\mathrm{r}}=0.985$

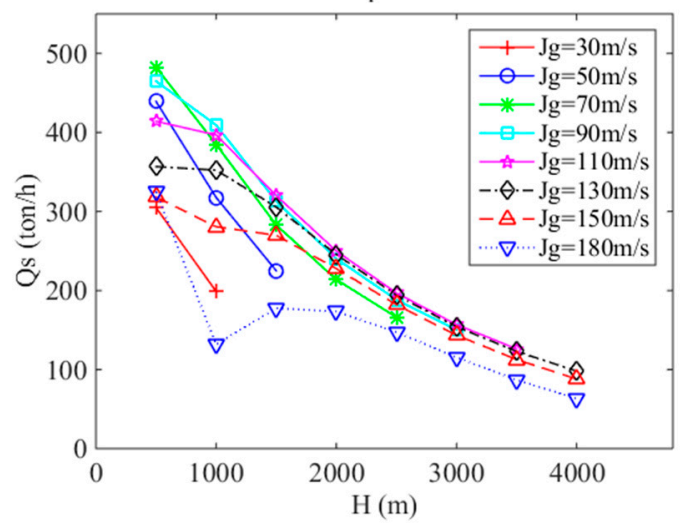

Figure 5. Figure of solid production rate $Q s$ influenced by submergence ratio $S_{r}$ at different mining depth $H$ and gas flux rate $J g$. The submergence ratio of (a-d) are 1.000, 0.995, 0.990, 0.985, respectively. 
Figure 6 depicts the relationship between the solid production rate and pipe diameter at different mining depths and gas flux rate with the submergence ratio of 0.990 and particle diameter of $5.0 \mathrm{~mm}$. Analyzing Figure $6 \mathrm{a}-\mathrm{d}$, a larger pipe diameter can increase the solid production rate significantly. For instance, when the mining depth is $500 \mathrm{~m}$ and gas flux rate is $70 \mathrm{~m} / \mathrm{s}$, the solid production rate is 487.6 ton/h in Figure 6a with a pipe diameter of $0.40 \mathrm{~m}$ and $143.8 \mathrm{ton} / \mathrm{h}$ in Figure $6 \mathrm{~d}$ with a pipe diameter of $0.25 \mathrm{~m}$. Additionally, a larger pipe diameter may also represent a larger applicable mining depth with the same gas flux rate which means the pipe diameter plays as a bottleneck to the solid production rate and the applicable mining depth. For instance, considering solid production rate more than 50 ton/h and gas flux rate of $150 \mathrm{~m} / \mathrm{s}$, the maximum mining depth of airlifting system with a pipe diameter of $0.40 \mathrm{~m}$ is $4500 \mathrm{~m}$, see Figure 6a, which is much larger than $2500 \mathrm{~m}$ of an airlifting system with a pipe diameter of $0.30 \mathrm{~m}$, see Figure 6c. Furthermore, analyzing Figure $6 \mathrm{~d}$, the airlifting system with gas flux rate of $180 \mathrm{~m} / \mathrm{s}$ produces the largest solid production rate at the mining depth of $500 \mathrm{~m}$. However, with the increase of pipe diameter, the airlifting system with gas flux rate of $70 \mathrm{~m} / \mathrm{s}$ produces the largest solid production rate. It means that, for a special working condition of an airlifting system, the maximum solid production rate is determined by the mining depth, gas flux rate, and pipe diameter together.

(a) $\mathrm{D}_{\mathrm{i}}=0.40 \mathrm{~m}$

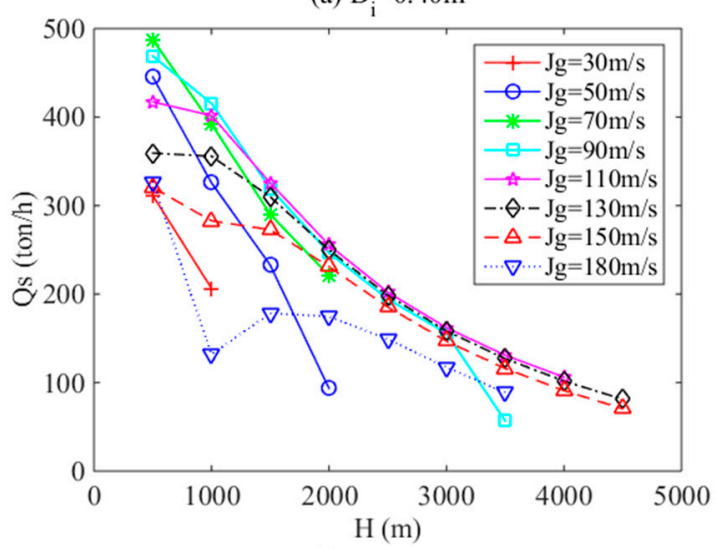

(c) $\mathrm{D}_{\mathrm{i}}=0.30 \mathrm{~m}$

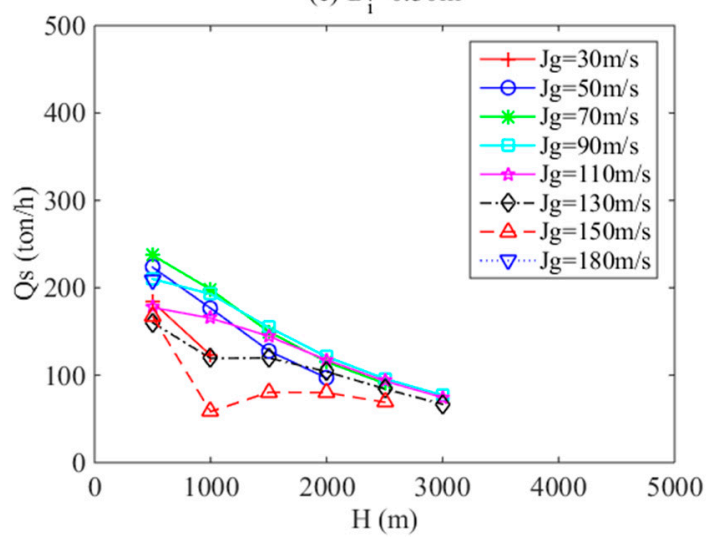

(b) $\mathrm{D}_{\mathrm{i}}=0.35 \mathrm{~m}$

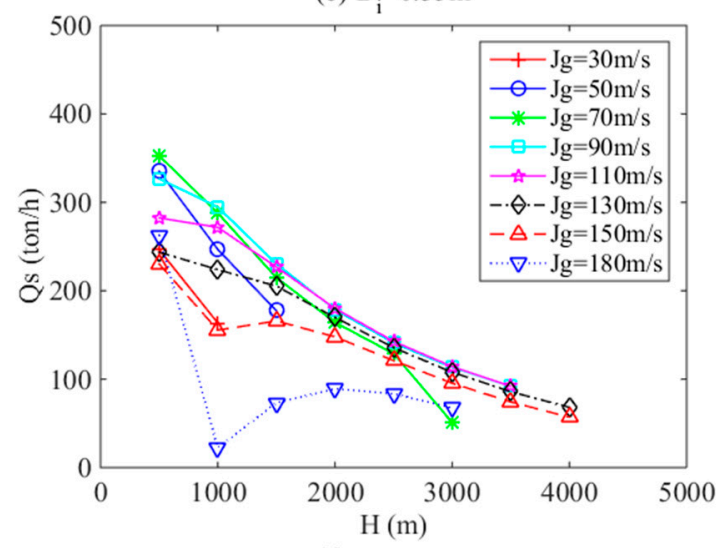

(d) $\mathrm{D}_{\mathrm{i}}=0.25 \mathrm{~m}$

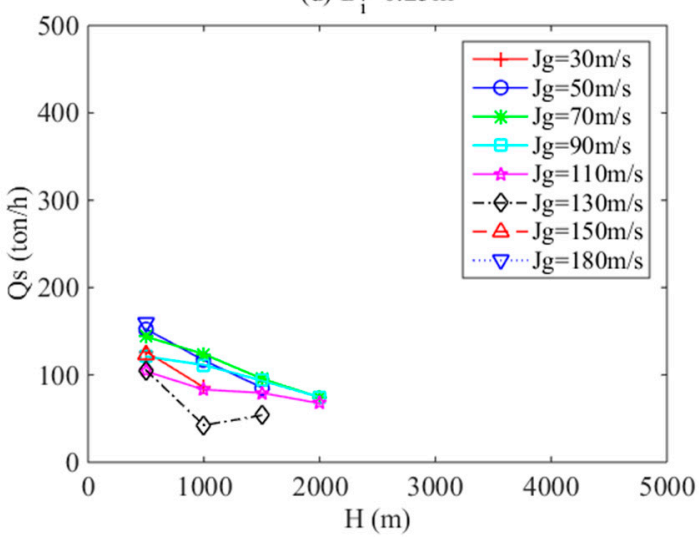

Figure 6. Figure of solid production rate $Q s$ influenced by pipe diameter $D_{i}$ at different mining depth $H$ and gas flux rate $J g$. The pipe diameter of $(\mathbf{a}-\mathbf{d})$ are $0.40,0.35,0.30,0.25 \mathrm{~m}$, respectively.

Figure 7 depicts the relationship between the solid production rate and particle diameter at different mining depth and gas flux rate with the submergence ratio of 0.990 and pipe diameter of $0.30 \mathrm{~m}$. Analyzing Figure $7 \mathrm{a}-\mathrm{d}$, airlifting small particles has a higher solid production rate comparing to the large particles as expected. For instance, in Figure $7 \mathrm{a}$, the solid production rate is 223.5 ton $/ \mathrm{h}$ when the mining depth is $500 \mathrm{~m}$ and gas flux rate is $50 \mathrm{~m} / \mathrm{s}$. However, in Figure $7 \mathrm{~d}$, with the same mining depth and gas flux rate, the solid production rate is only 148.8 ton $/ \mathrm{h}$, which means lifting small 
particles is much easier than lifting large particles. The significant difference may be because the drag forces and pressure losses of large particles in the transport process are larger than that of the small particles [3,26]. Additionally, the airlifting system with gas flux rate of $180 \mathrm{~m} / \mathrm{s}$ is only applicable at the depth of $500 \mathrm{~m}$ when the pipe diameter is $0.30 \mathrm{~m}$. It can be explained as that pipe diameter plays as a more significant bottleneck to the solid production rate comparing with the particle diameter, see Figures $6 \mathrm{c}$ and 7 . Furthermore, there are different degrees of reductions of solid production rate at the mining depth of $500 \mathrm{~m}$ lifting $30 \mathrm{~mm}$ particles, see Figure $7 \mathrm{~d}$, it means that the particle diameter plays as a bottleneck to the solid production rate when the gas flux rate is smaller than $130 \mathrm{~m} / \mathrm{s}$ comparing with the airlifting system transport particles of $5 \mathrm{~mm}$, see Figure $7 \mathrm{a}$.

(a) $d_{s}=5 \mathrm{~mm}$

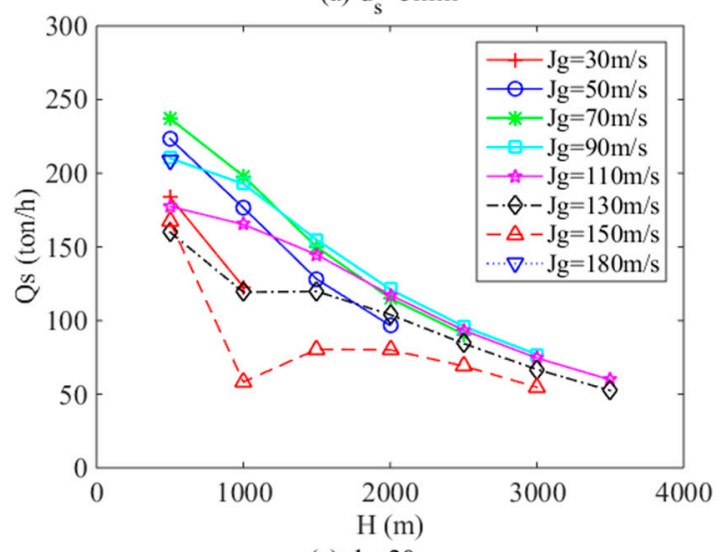

(c) $\mathrm{d}_{\mathrm{s}}=20 \mathrm{~mm}$

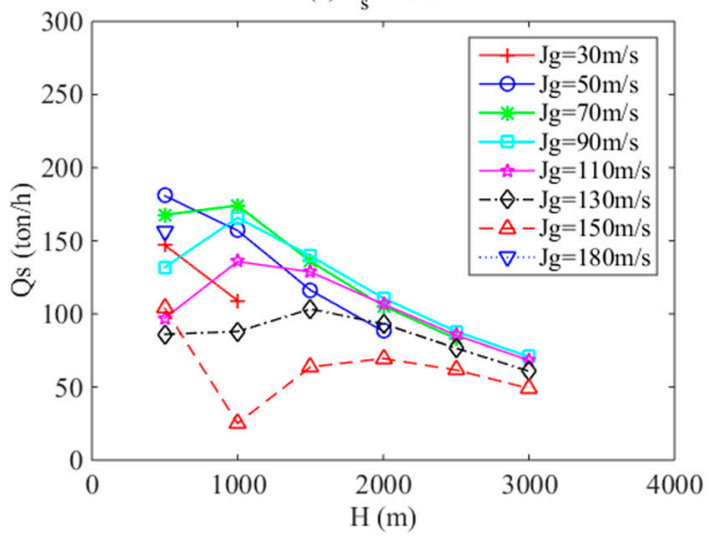

(b) $d_{s}=10 \mathrm{~mm}$

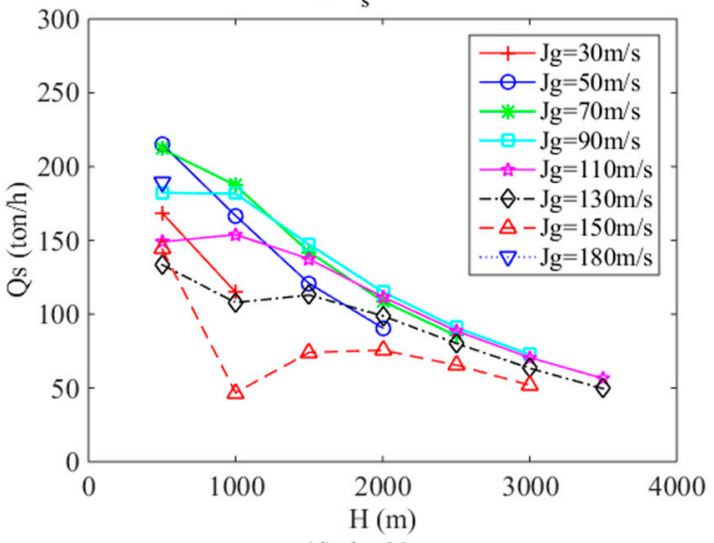

(d) $\mathrm{d}_{\mathrm{s}}=30 \mathrm{~mm}$

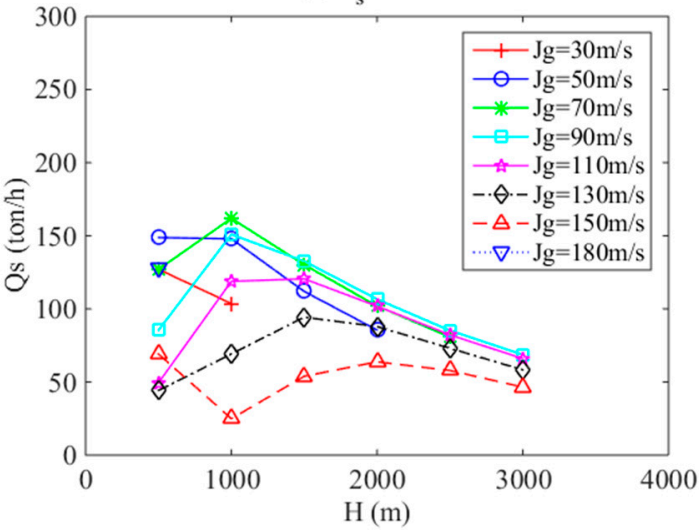

Figure 7. Figure of solid production rate $Q s$ influenced by particle diameter $d_{s}$ at different mining depth $H$ and gas flux rate $J g$. The particle diameter of $(\mathbf{a}-\mathbf{d})$ are 5, 10, 20, $30 \mathrm{~mm}$, respectively.

\subsection{Energy Consumption per Tonnage of Minerals Analysis}

Only considering the total solid production rate is not enough to obtain an optimal transport plan, energy consumption per tonnage of mineral is also an important parameter which can influence the stakeholder's final decision. In this section, the relationships between energy consumption per tonnage of mineral and submergence ratio, pipe diameter, mining depth, particle diameter, and gas flux rate are presented.

Figure 8 depicts the relationship between the energy consumption per tonnage of mineral and submergence ratio at different mining depth and gas flux rate with pipe diameter of $0.40 \mathrm{~m}$ and particle diameter of $5.0 \mathrm{~mm}$. Analyzing Figure $8 \mathrm{a}-\mathrm{d}$, it is obvious that the energy consumption per tonnage of mineral increases with the increase of mining depth. Although airlifting efficiency increases with the mining depth [15], it is notable that the higher efficiency cannot guarantee lower energy consumption per tonnage of mineral. In other words, airlifting with the same gas flux rate used on smaller mining 
depth has a better performance with a larger solid production rate and smaller energy consumption per tonnage of minerals. Additionally, as the values of submergence ratio is set within a small changing range from 0.985 to 1.000 , there are not so many significant differences among Figure $8 \mathrm{a}-\mathrm{d}$, which is also consistent with the results in Figure 5. By analyzing the data in Figure 8, it is proved that larger submergence ratio may also represent slightly smaller energy consumption per tonnage of mineral. For instance, when the gas flux rate is $180 \mathrm{~m} / \mathrm{s}$ and mining depth is $4000 \mathrm{~m}$, the energy consumption per tonnage of mineral with the submergence ratio of 1.000 is $190.4 \mathrm{kWh} /$ ton, see Figure $8 \mathrm{a}$, which is smaller than that of $208.1 \mathrm{kWh} /$ ton with the submergence ratio of 0.985 , see Figure $8 \mathrm{~d}$. It can be explained as that a larger submergence ratio means a smaller lifting depth when the total mining depth is the same. Furthermore, compared to the airlifting system with gas flux rate smaller than $150 \mathrm{~m} / \mathrm{s}$, the airlifting system with gas flux rate of $180 \mathrm{~m} / \mathrm{s}$ consumes much more energy consumption per tonnage of mineral. It means the flux rate of $180 \mathrm{~m} / \mathrm{s}$ is too much large for the airlifting system with pipe diameter of $0.40 \mathrm{~m}$ and particle diameter of $5 \mathrm{~mm}$.

(a) $\mathrm{S}_{\mathrm{r}}=1.000$

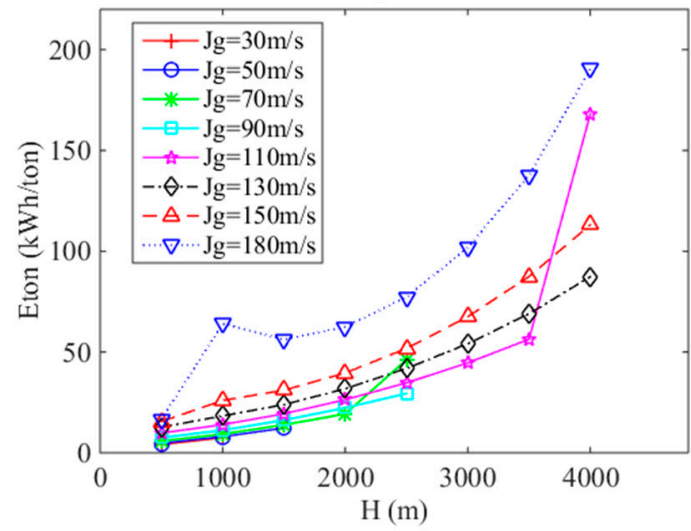

(c) $\mathrm{S}_{\mathrm{r}}=0.990$

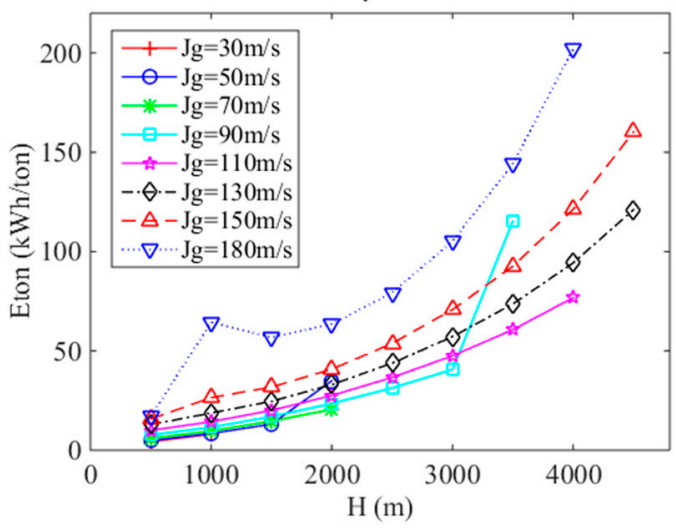

(b) $\mathrm{S}_{\mathrm{r}}=0.995$

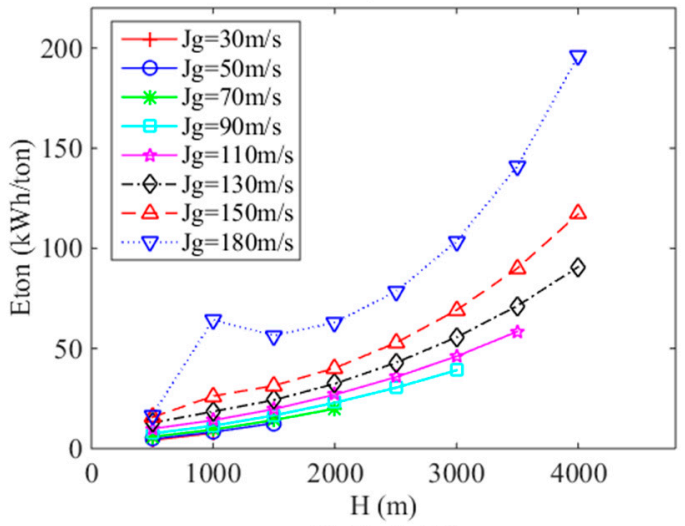

(d) $\mathrm{S}_{\mathrm{r}}=0.985$

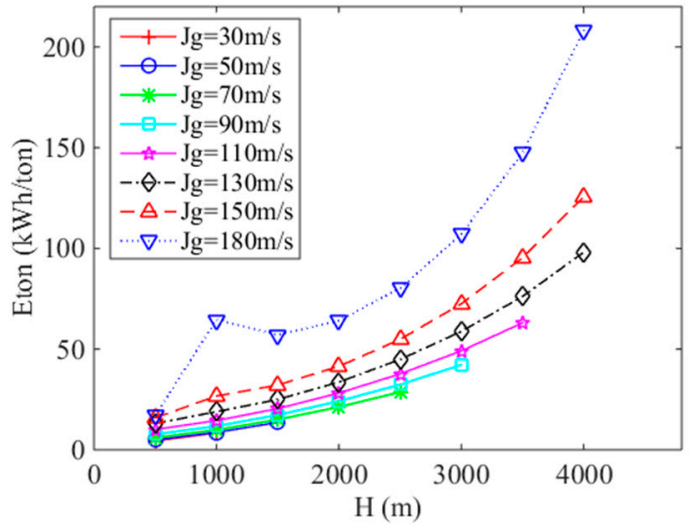

Figure 8. Figure of energy consumption per tonnage of mineral Eton influenced by submergence ratio $S_{r}$ at different mining depth $H$ and gas flux rate $J g$. The submergence ratio of (a-d) are 1.000, 0.995, 0.990, 0.985, respectively.

Figure 9 depicts the relationship between the energy consumption per tonnage of mineral and pipe diameter at different mining depth and gas flux rate with the submergence ratio of 0.990 and particle diameter of $5.0 \mathrm{~mm}$. Analyzing Figure $9 \mathrm{a}-\mathrm{d}$, it is notable that airlifting with a larger pipe diameter can be used for a deeper mining depth. For instance, when the gas flux rate is $150 \mathrm{~m} / \mathrm{s}$, the maximum airlifting depth with a $0.40 \mathrm{~m}$ pipe diameter is $4500 \mathrm{~m}$, see Figure $9 \mathrm{a}$, and $2500 \mathrm{~m}$ with a $0.30 \mathrm{~m}$ pipe diameter; see Figure $9 \mathrm{c}$. This is because when the gas flux rate is large enough, pipe diameter has become the bottleneck of the airlifting applicable depth. For airlifting system with gas flux rate of $180 \mathrm{~m} / \mathrm{s}$, its energy consumption lifting per tonnage of mineral is much larger than 
the airlifting system with smaller gas flux rate, see Figure 9a,b. Additionally, the curve of energy consumption per tonnage of mineral changing with the mining depth is also significantly different with the other changing curves. It may be caused by the complicated interactions between the airlifting efficiency and the mining depth. An airlifting system with too much large gas flux rate could represent a large percentage of energy waste. Furthermore, as the models mentioned in this paper are validated by the small scaled mechanism with a lower gas flux rate, the model may be not applicable to the too much large gas flux rate completely. Comparing Figure 9a to Figure 9d, the airlifting system with gas flux rate of $30 \mathrm{~m} / \mathrm{s}$ consumes the minimum energy consumption per tonnage of mineral. Therefore, the airlifting performance in terms of energy consumption per tonnage of mineral, see Figure 9, is not completely consistent with that in terms of solid production rate, see Figure 6.

(a) $\mathrm{D}_{\mathrm{i}}=0.40 \mathrm{~m}$

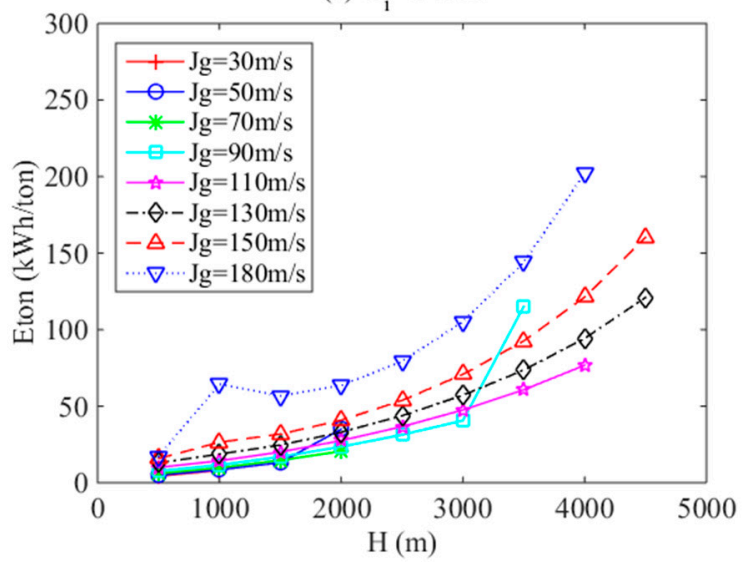

(c) $\mathrm{D}_{\mathrm{i}}=0.30 \mathrm{~m}$

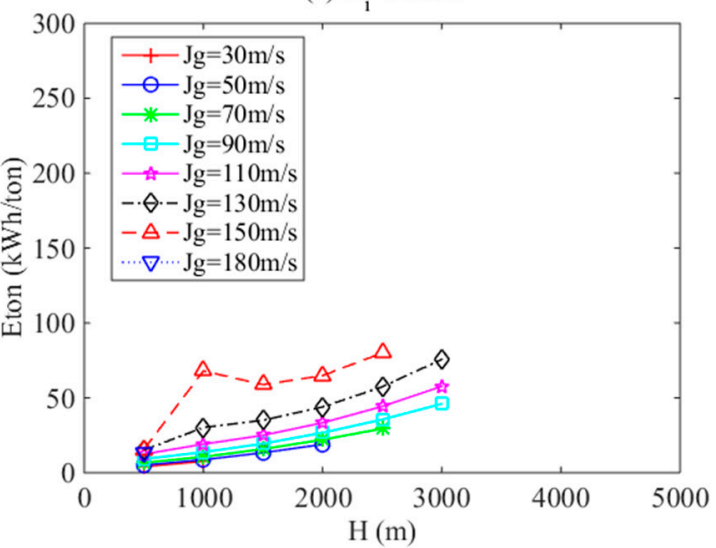

(b) $\mathrm{D}_{\mathrm{i}}=0.35 \mathrm{~m}$

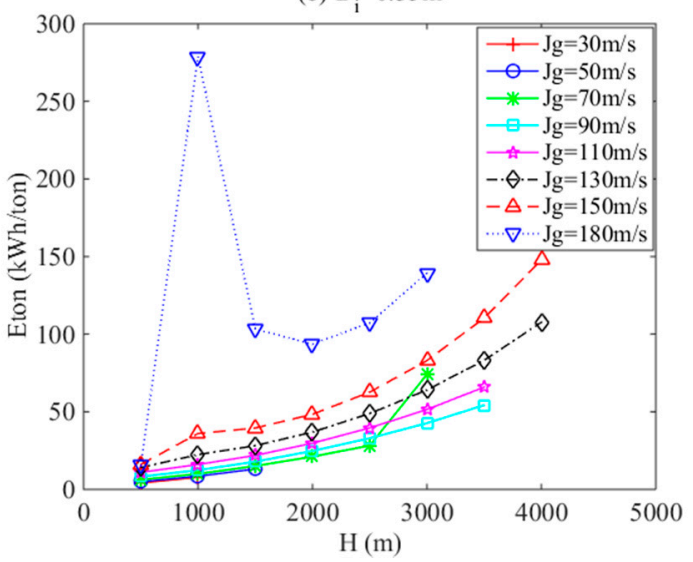

(d) $\mathrm{D}_{\mathrm{i}}=0.25 \mathrm{~m}$

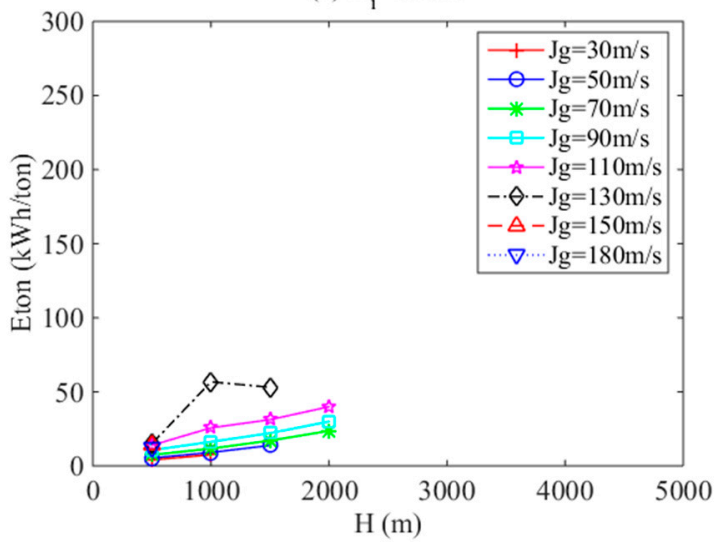

Figure 9. Figure of energy consumption per tonnage of mineral Eton influenced by pipe diameter $D_{i}$ at different mining depth $H$ and gas flux rate $J g$. The pipe diameter of (a-d) are $0.40,0.35,0.30,0.25$ $\mathrm{m}$, respectively.

Figure 10 depicts the relationship between the energy consumption per tonnage of mineral and particle diameter at different mining depth and gas flux rate with the submergence ratio of 0.900 and pipe diameter of $0.30 \mathrm{~m}$. Analyzing Figure $10 \mathrm{a}-\mathrm{d}$, the curves of airlifting system with gas flux rate of 30,50,70 and $90 \mathrm{~m} / \mathrm{s}$ are concentrated with the similar curve changing trend which are divergent when the gas flux rate is larger than $110 \mathrm{~m} / \mathrm{s}$. Additionally, the airlifting system transporting of small particles has a more concentrated and consistent curve changing trend. It means particle diameter may play as a significant bottleneck to the energy consumption per tonnage of mineral for large gas flux rate. It maybe also represent that the model utilized in this paper may be more suitable for fine particles and small gas flux rate which may also be used to explain the sudden increase of energy consumption per tonnage of mineral of gas flux rate at $150 \mathrm{~m} / \mathrm{s}$. Obviously, with the increase of mining depth, the 
energy consumption per tonnage of mineral is also increasing. Comparing Figures 7 and 10, it is shown that the airlifting system with gas flux rate of $150 \mathrm{~m} / \mathrm{s}$ produces the minimum solid production rate and consumes the maximum energy consumption per tonnage of mineral. It means the gas flux rate of $150 \mathrm{~m} / \mathrm{s}$ is not suitable to select as the airlifting parameter under the calculated working conditions.
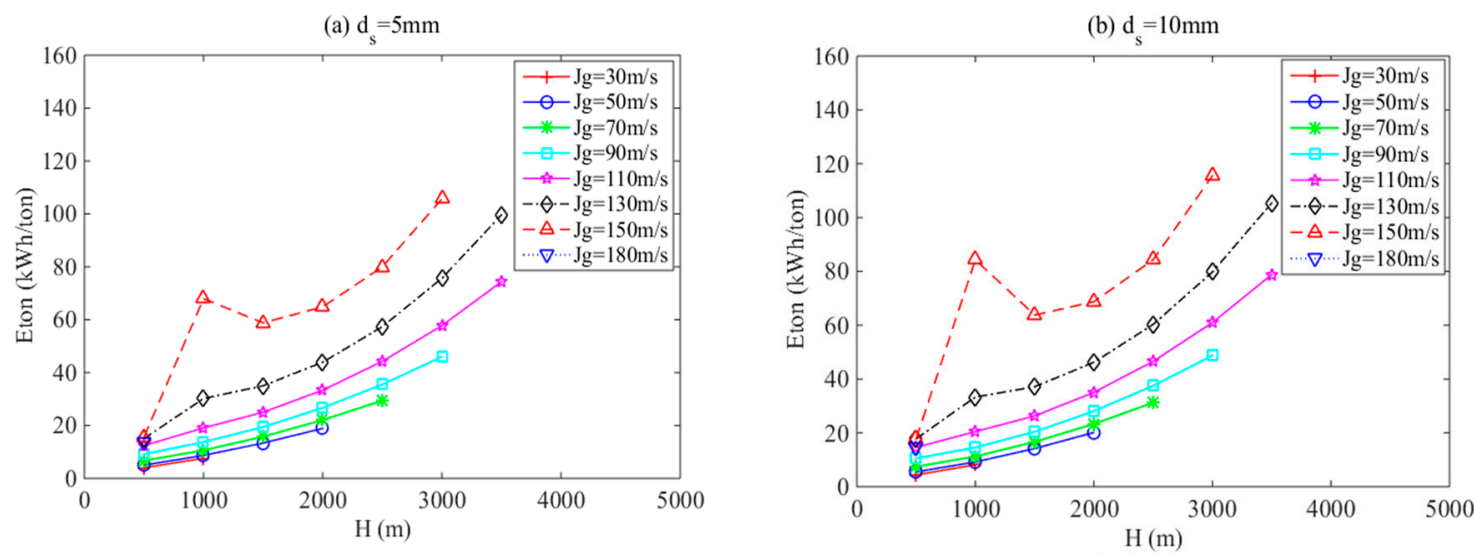

(c) $d_{s}=20 \mathrm{~mm}$
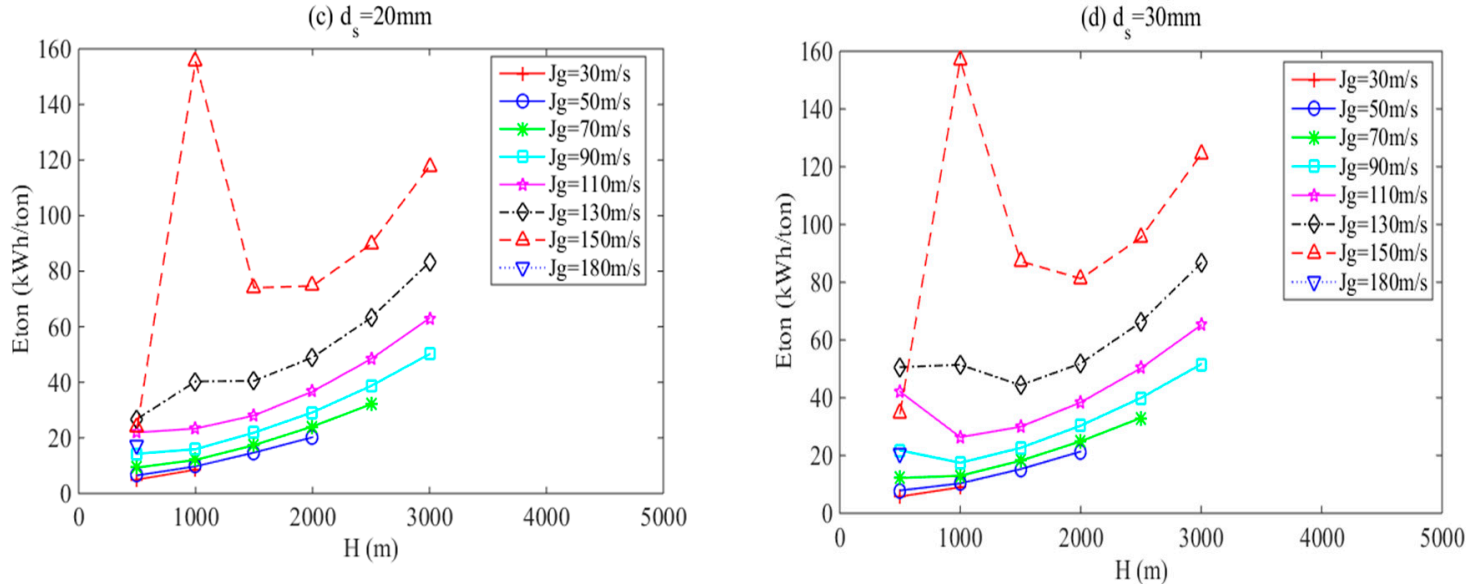

Figure 10. Figure of energy consumption per tonnage of mineral Eton influenced by particle diameter $d_{s}$ at different mining depth $H$ and gas flux rate $J g$. The particle diameter of (a-d) are 5, 10, 20, 30 $\mathrm{mm}$, respectively.

\subsection{Profitability per Tonnage of Mineral Analysis}

The given parameters to calculate the profitability per tonnage of mineral are shown in Table $2[12,17]$. Profitability per tonnage of mineral is also an important parameter to determine an optimal transport plan of DSM projects. In this section, the relationships between profitability per tonnage of mineral and submergence ratio, pipe diameter, mining depth, particle diameter, and gas flux rate are researched.

Table 2. The Calculation Parameters Used for the Economic Comparison Partially Based on References [12,17].

\begin{tabular}{|c|c|c|c|c|c|}
\hline Parameters & Value & Parameters & Value & Parameters & Value \\
\hline$\varepsilon_{1}(-)$ & 30 & $M_{s v}\left(10^{6} \cdot \$\right)$ & 495 & $M_{\mathcal{C}_{-} p}\left(10^{6} \cdot \$\right)$ & 750 \\
\hline$W_{i}\left(10^{6} \cdot \$ /\right.$ year $)$ & 0.45 & $R(\$ / \mathrm{kWh})$ & 0.2 & $a(-)$ & $4.28 \%$ \\
\hline$K_{m \_k}(\$ /$ ton $)$ & 1.2 & $K_{t \_k}(\$ /$ ton $)$ & 1.2 & $K_{p_{-} k}(\$ /$ ton $)$ & 0.8 \\
\hline$s$ (day) & 300 & $N$ (year) & 20 & $M_{\text {ot }}\left(10^{6} \cdot \$\right)$ & 35 \\
\hline
\end{tabular}


Figure 11 depicts the relationship between the profitability per tonnage of mineral and submergence ratio at different mining depth and gas flux rate with pipe diameter of $0.40 \mathrm{~m}$ and particle diameter of $5.0 \mathrm{~mm}$. Although there is not a big scale difference among Figure 11a-b, by analyzing the data in Figure 11, the airlifting system with a larger submergence ratio has a slightly better performance than that with a smaller submergence ratio in terms of the profitability per tonnage of mineral. This is also correct in terms of the minerals solid production rate; see Figure 5, and energy consumption per tonnage of mineral, see Figure 8. It is obvious that lifting minerals from a smaller mining depth have a significantly better performance of airlifting systems in terms of profitability lifting per tonnage of mineral. Additionally, only when the mining depth is less than roughly $2500 \mathrm{~m}$, DSM projects can be profitable, or it will lose money. It means that the applicable mining depth range of airlifting technology utilized in DSM systems is limited. For instance, when the submergence ratio is 0.985 , see Figure 11d, the DSM system with airlifting mining depth of $3000 \mathrm{~m}$ is not profitable at all. Comparing Figures 5, 8 and 11, the solid production rate decreases with the mining depth increase which may also lead to a significant decrease of profitability per tonnage of mineral. Additionally, when airlifting approaches its maximum applicable depth, there may be a sudden decrease of profitability lifting per tonnage of mineral, e.g., the airlifting system with gas flux rate of $50 \mathrm{~m} / \mathrm{s}$ and submergence ratio of 0.990 , see Figure 11c, which is also manifested on the sudden decrease of solid production rate, see Figure 5, and sudden increase of energy consumption per tonnage of mineral, see Figure 8.

(a) $\mathrm{S}_{\mathrm{r}}=1.000$

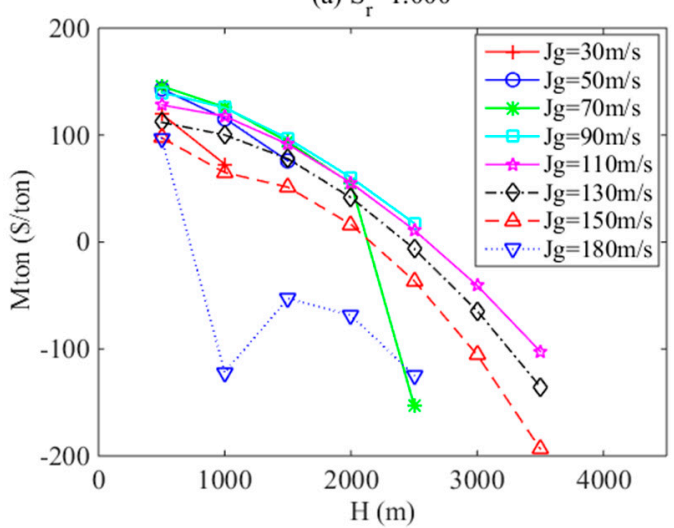

(c) $\mathrm{S}_{\mathrm{r}}=0.990$

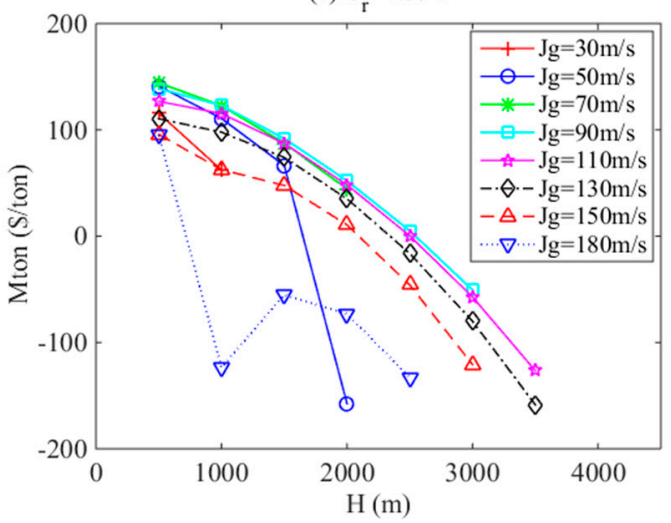

(b) $\mathrm{S}_{\mathrm{r}}=0.995$

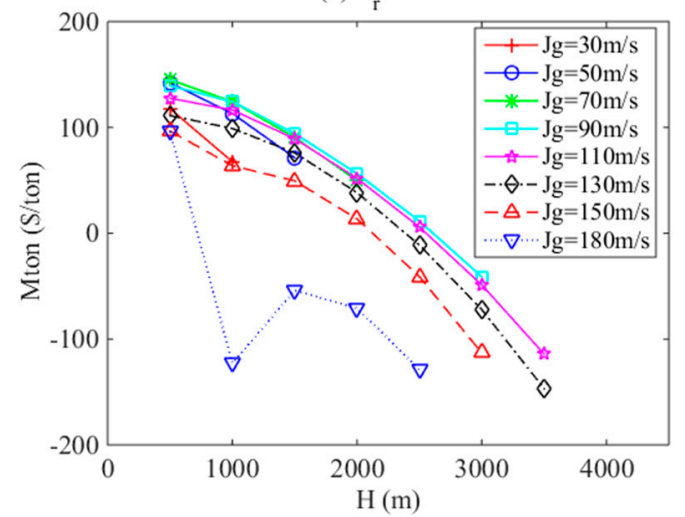

(d) $\mathrm{S}_{\mathrm{r}}=0.985$

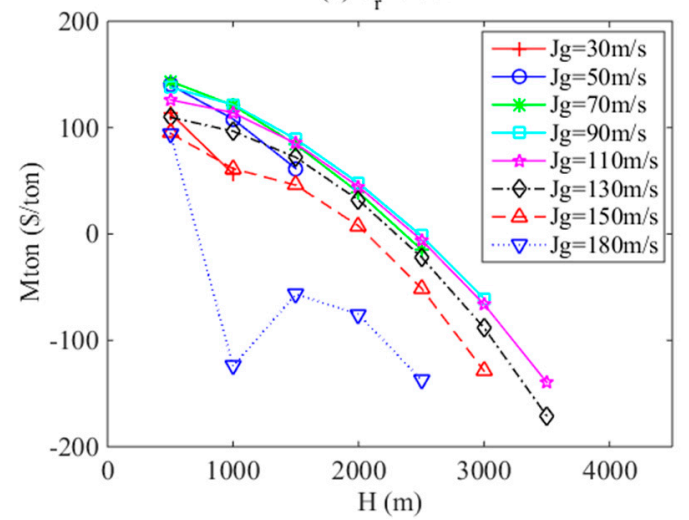

Figure 11. Figure of profitability per tonnage of mineral Mton influenced by submergence ratio $S_{r}$ at different mining depth $H$ and gas flux rate $J g$. The submergence ratio of (a-d) are 1.000, 0.995, 0.990, 0.985 , respectively.

Figure 12 depicts the relationship between the profitability per tonnage of mineral and pipe diameter at different mining depth and gas flux rate with the submergence ratio of 0.990 and particle diameter of $5.0 \mathrm{~mm}$. Comparing Figure $12 \mathrm{a}-\mathrm{d}$, it can be concluded that airlifting system with a larger 
pipe diameter, e.g., $0.40 \mathrm{~m}$, has a better performance than that with a small pipe diameter, e.g., $0.25 \mathrm{~m}$, in terms of the profitability per tonnage of mineral. For instance, when the mining depth is $500 \mathrm{~m}$ and gas flux rate is $180 \mathrm{~m}$, the profitability of airlifting system with $0.40 \mathrm{~m}$ pipe diameter is $95.2 \$ /$ ton which is much larger than $16.8 \$$ /ton of airlifting system with $0.25 \mathrm{~m}$ pipe diameter. Additionally, analyzing Figure $12 \mathrm{a}-\mathrm{d}$, neither the largest, nor the smallest gas flux rate generates the maximum profitability per tonnage of mineral. It is because for each set of mining depth and pipe diameter, there exists an optimal gas flux rate to obtain the maximum profitability per tonnage of mineral. Furthermore, comparing the airlifting performances in Figure $12 \mathrm{a}, \mathrm{d}$, it is notable that airlifting system is more suitable working with a large pipe diameter in terms of profitability lifting per tonnage of mineral, which is also consistent with the results of solid production rate, see Figure 6, and energy consumption per tonnage of mineral, see Figure 9. It is because the pipe diameter has become a bottleneck to the performances of airlifting system in Figure 12.

(a) $\mathrm{D}_{\mathrm{i}}=0.40 \mathrm{~m}$

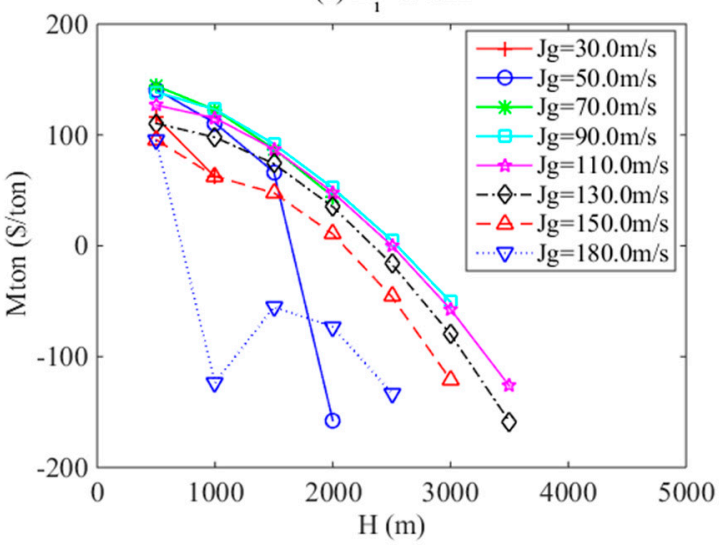

(c) $\mathrm{D}_{\mathrm{i}}=0.30 \mathrm{~m}$

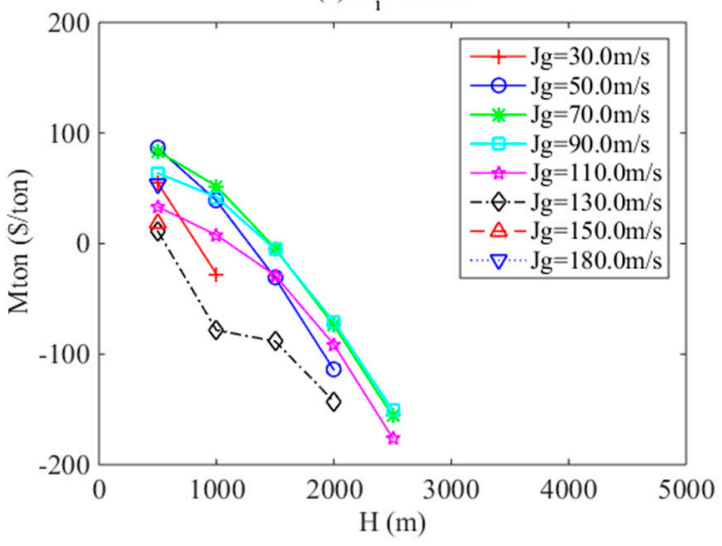

(b) $\mathrm{D}=0.35 \mathrm{~m}$

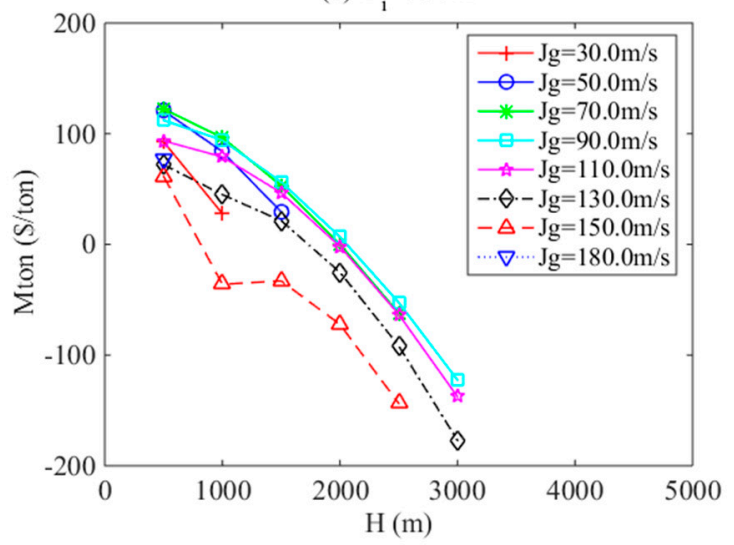

(d) $\mathrm{D}_{\mathrm{i}}=0.25 \mathrm{~m}$

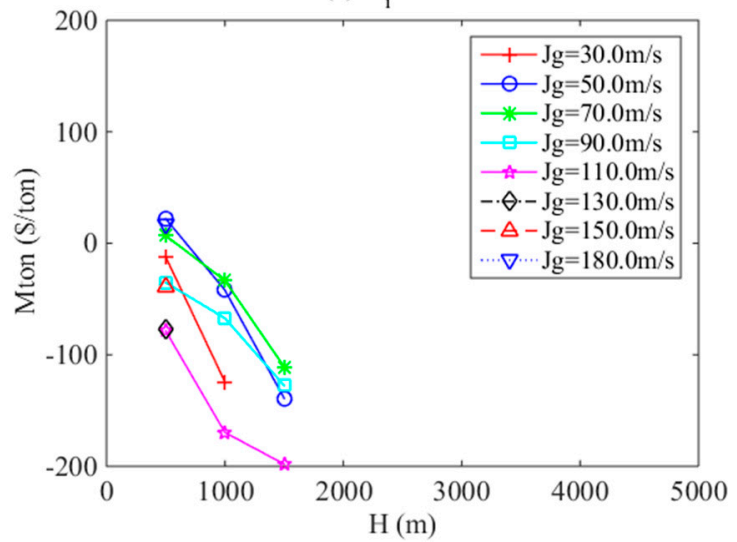

Figure 12. Figure of profitability per tonnage of mineral Mton influenced by pipe diameter $D_{i}$ at different mining depth $H$ and gas flux rate $J g$. The pipe diameter of $(\mathbf{a}-\mathbf{d})$ are $0.40,0.35,0.30,0.25$ $\mathrm{m}$, respectively.

Figure 13 depicts the relationship between the profitability per tonnage of mineral and particle diameter at different mining depth and gas flux rate with the submergence ratio of 0.990 and pipe diameter of $0.30 \mathrm{~m}$. Analyzing Figure $13 \mathrm{a}-\mathrm{d}$, it is notable that lifting small particles has a better performance than large particles, which is almost correct in terms of total solid production rate, see Figure 7, and energy consumption per tonnage of mineral, see Figure 10. Additionally, when the particles diameter is small, e.g., $5 \mathrm{~mm}$, airlifting system working at a small mining depth has a better performance than at a larger depth, which is caused by the significant increase of anti-gravitational energy consumption. In Figure 13c,d, for the airlifting system with gas flux rate of 70, 90, and $110 \mathrm{~m} / \mathrm{s}$, 
there is a profitability decrease at the mining depth of $500 \mathrm{~m}$. It can be explained as that the profitability lifting per tonnage of mineral is influenced by the mining depth, particle diameter and gas flux rate together. The particle diameter plays as a bottleneck to the airlifting performances in Figure 13c,d.
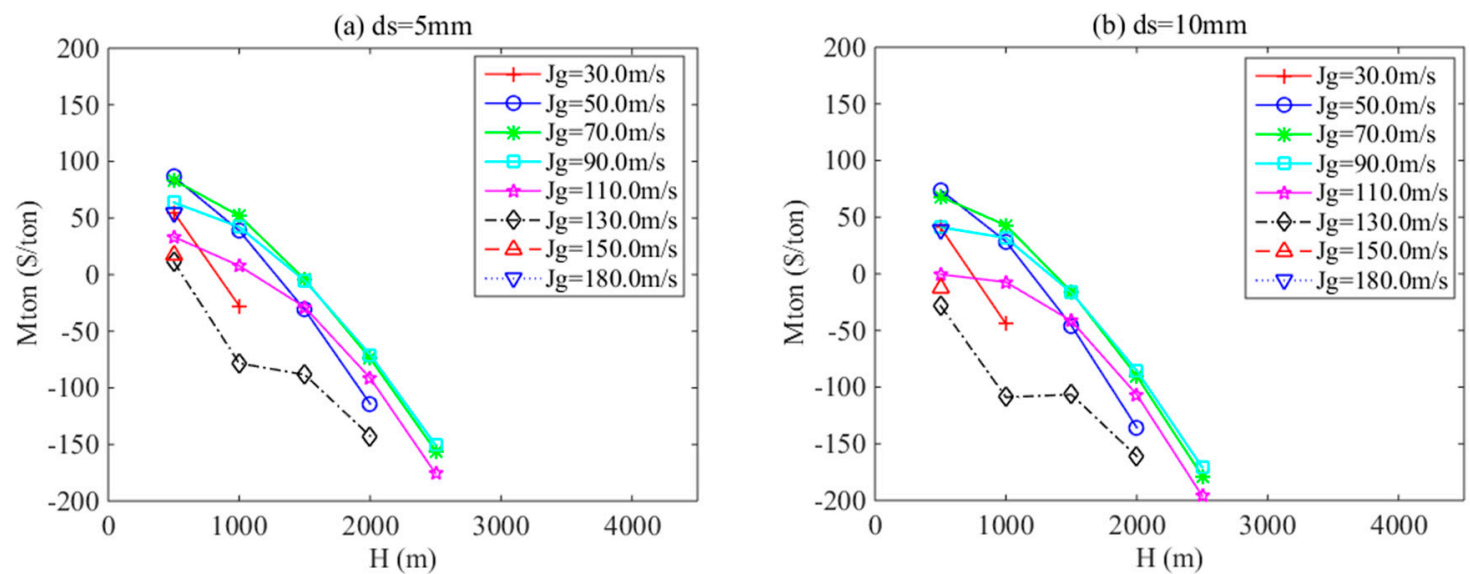

(c) $\mathrm{ds}=20 \mathrm{~mm}$
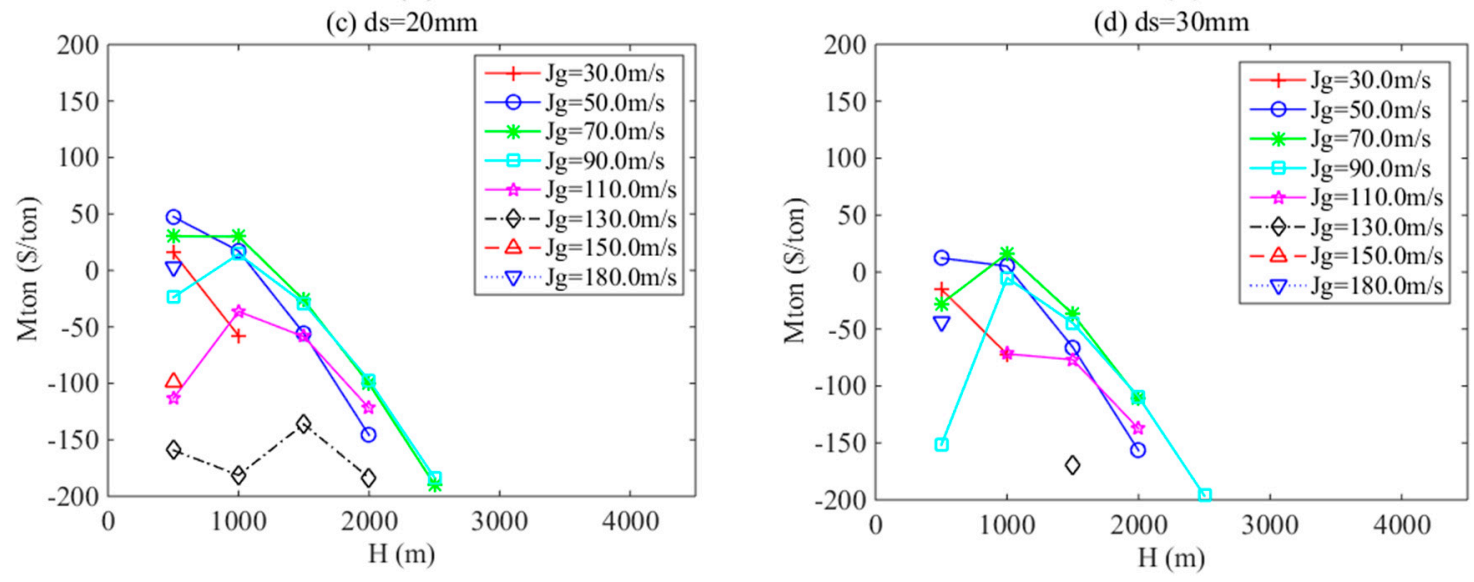

Figure 13. Figure of profitability per tonnage of mineral Mton influenced by particle diameter $d_{s}$ at different mining depth $H$ and gas flux rate $J g$. The particle diameter of (a-d) are 5, 10, 20, $30 \mathrm{~mm}$, respectively.

\section{Conclusions}

The research in this paper focuses on technological feasibility and profitability analyses of DSM projects utilizing airlifting technology. The conclusions are as follows:

- The numerical calculation method considers the compressibility of the gas, which is caused by the large mining depth in engineering conditions, on the basis of the original models of Yoshinaga and Sato, and Kassab et al. Additionally, the numerical calculation method considers complete set of parameters, which consists of the submergence ratio, mining depth, pipe diameter, particle diameter, and gas flux rate.

- A higher submergence ratio of airlifting system in DSM projects has slightly better performances than that with a smaller one in terms of the solid production rate, energy consumption per tonnage of mineral, and the profitability per tonnage of mineral.

- $\quad$ Large pipe diameter can increase the solid production rate significantly; see Figure 6. Analyzing Figure $9 a-d$, it is notable that airlifting with a larger pipe diameter can be used for a deeper mining depth. Additionally, when airlifting approaches its maximum applicable depth, there may exist a sudden increase of energy consumption per tonnage of mineral, see Figure 9, and a sudden decrease of profitability lifting per tonnage of mineral, see Figure 12. A larger pipe diameter and gas flux rate cannot guarantee a better airlifting performance. It is because for each set of mining 
depth and pipe diameter, there exists an optimal set of gas flux rate and pipe diameter to obtain the maximum profitability per tonnage of mineral.

- Transporting small particles has a better performance than large particles in terms of its profitability, which is almost correct in terms of total solid production rate and energy consumption per tonnage of mineral.

In future research, the method how to obtain an optimal transport plan considering the solid production rate, energy consumption per tonnage of mineral, and profitability per tonnage of mineral should be researched. In addition, the scale effect elaborated in Section 3.1.3 should be considered further combining with some industrial scaled prototype parameters of airlifting in DSM projects. Besides the scale effects existing between the up-scaled model and industrial scaled prototype of airlifting model, flow pattern differences should also be considered in the future research.

Acknowledgments: This research is supported by the China Scholarship Council under grant 201506950007. Additionally, I appreciate the generous helps from Irwin Liang and three anonymous reviewers for editing and reviewing my manuscript.

Author Contributions: Wenbin Ma, Cees van Rhee and Dingena Schott worked together to analyze the technological and profitable analysis of airlifting in deep sea mining systems and approved the manuscript.

Conflicts of Interest: The authors declare no conflict of interest.

\section{References}

1. Amos, A.F.; Roels, O.A. Environment aspects of manganese nodule mining. Mar. Policy 1977, 1, 156-163. [CrossRef]

2. Pougatch, K.; Salcudean, M. Numerical modelling of deep sea air-lift. Ocean Eng. 2008, 35, 1173-1182. [CrossRef]

3. Kassab, S.Z.; Kandil, H.A.; Warda, H.A.; Ahmed, W.H. Experimental and analytical investigations of airlift pumps operating in three-phase flow. Chem. Eng. J. 2007, 131, 273-281. [CrossRef]

4. Birney, K.; Griffin, A.; Gwiazda, J.; Kefauver, J.; Nagai, T.; Varchol, D. Potential deep-sea mining of seafloor massive sulfides: A case study in Papua New Guinea. Master Thesis, Donald Bren School of Environmental Science and Management, Irvine, CA, USA, 2006.

5. Hatta, N.; Fujimoto, H.; Isobe, M.; Kang, J.S. Theoretical analysis of flow characteristics of multiphase mixtures in a vertical pipe. Int. J. Multiph. Flow 1998, 24, 539-561. [CrossRef]

6. Yoshinaga, T.; Sato, Y. Performance of an air-lift pump for conveying coarse particles. Int. J. Multiph. Flow 1996, 22, 223-238. [CrossRef]

7. Hatta, N.; Omodaka, M.; Nakajima, F.; Takatsu, T.; Fujimoto, H.; Takuda, H. Predictable Model for Characteristics of One-Dimensional Solid-Gas-Liquid Three-Phase Mixtures Flow Along a Vertical Pipeline with an Abrupt Enlargement in Diameter. ASME J. Fluids Eng. 1999, 121, 330-342. [CrossRef]

8. Margaris, D.P.; Papanikas, D.G. A generalized gas-liquid-solid three-phase flow analysis for airlift pump design. Trans. Am. Soc. Mech. Eng. J. Fluid Eng. 1997, 119, 995-1002. [CrossRef]

9. Hong, S.; Choi, J.S.; Hong, S.W. Experimental study on effects of pipe inclination in airlift water pumping. In Proceedings of the Fifteenth International Offshore and Polar Engineering Conference, Seoul, Korea, 19-25 June 2005; International Society of Offshore and Polar Engineers: Mountain View, CA, USA, 2005; pp. $421-425$.

10. Nam-Cheol, C.; Hwang, I.J.; Chae-Moon, L.E.E.; Jung-Won, P.A.R.K. An experimental study on the airlift pump with air jet nozzle and booster pump. J. Environ. Sci. 2009, 21, S19-S23.

11. Fan, W.; Chen, J.; Pan, Y.; Huang, H.; Chen, C.T.A.; Chen, Y. Experimental study on the performance of an air-lift pump for artificial upwelling. Ocean Eng. 2013, 59, 47-57. [CrossRef]

12. Ma, W.; Schott, D.; Lodewijks, G. Continuous line bucket lifting versus pipe lifting. J. Offshore Mech. Arct. Eng. 2017, 139, 051704. [CrossRef]

13. Dedegil, M.Y. Principles of Air-Lift Techniques. In Encyclopedia Fluid Mechanics; Gulf: Houston, TX, USA, 1987; Chapter 12; p. 4. 
14. Sato, Y.; Yoshinaga, T.; Sadatomi, M. Data and empirical correlation for the mean velocity of coarse particles in a vertical three-phase air-wate solid particle flow. In Proceedings of the International Conference on Multiphase Flows '91-Tsukuba, Tsukuba, Japan, 24-27 September 1991; Volume 1, pp. 363-366.

15. Schulte, S.A. Vertical Transport Methods in Deep Sea Mining; Delft University of Technology: Delft, The Netherlands, 2013; Chapter 4; pp. 96-110.

16. Reinemann, D.J. A Theoretical and Experimental Study of Airlift Pumping and Aeration with Reference to Aquacultural Applications. Ph.D. Thesis, Cornell University, Ithaca, NY, USA, 1987.

17. Sharma, R. Deep-sea mining: Economic, technical, technological, and environmental considerations for sustainable development. Mar. Technol. Soc. J. 2011, 45, 28-41. [CrossRef]

18. Norgate, T.E.; Jahanshahi, S.; Rankin, W.J. Assessing the environmental impact of metal production processes. J. Clean. Prod. 2007, 15, 838-848. [CrossRef]

19. Stenning, A.H.; Martin, C.B. An analytical and experimental study of air-lift pump performance. J. Eng. Power 1968, 90, 106-110. [CrossRef]

20. Griffith, P. The Prediction of Low-Quality Boiling Voids. J. Heat Transf. 1964, 86, 327-333. [CrossRef]

21. Navarro, A.; Begovich, O.; Besançon, G.; Dulhoste, J.F. Real-time leak isolation based on state estimation in a plastic pipeline. Asian J. Control 2017, 19, 255-265. [CrossRef]

22. Heller, V. Scale effects in physical hydraulic engineering models. J. Hydraulic Res. 2011, 49, $293-306$. [CrossRef]

23. Hoagland, P.; Beaulieu, S.; Tivey, M.A.; Eggert, R.G.; German, C.; Glowka, L.; Lin, J. Deep-sea mining of seafloor massive sulfides. Mar. Policy 2010, 34, 728-732. [CrossRef]

24. Taitel, Y.; Bornea, D.; Dukler, A.E. Modelling flow pattern transitions for steady upward gas-liquid flow in vertical tubes. AIChE J. 1980, 26, 345-354. [CrossRef]

25. Doyle, R.L.; Halkyard, J.E. Large scale airlift experiments for application to deep ocean mining. In Proceedings of the 26th International Conference on Offshore Mechanics and Arctic Engineering, San Diego, CA, USA, 10-15 June 2007; American Society of Mechanical Engineers: New York, NY, USA, 2007; pp. 27-36.

26. Kato, H.; Miyazawa, T.; Timaya, S.; Iwasaki, T. A studyof an air-lift pump for solid particles and its application to marine engineering. JSME 1975, 18, 286-294. [CrossRef]

(C) 2017 by the authors. Licensee MDPI, Basel, Switzerland. This article is an open access article distributed under the terms and conditions of the Creative Commons Attribution (CC BY) license (http:/ / creativecommons.org/licenses/by/4.0/). 